\title{
Expression of Molecules Associated with Neuronal Plasticity in the Striatum after Aspiration and Thermocoagulatory Lesions of the Cerebral Cortex in Adult Rats
}

\author{
F. G. Szele, C. Alexander, and M.-F. Chesselet \\ Department of Pharmacology, The University of Pennsylvania, Philadelphia, Pennsylvania 19104
}

\begin{abstract}
Like the hippocampus, the striatum receives excitatory afferents from the cerebral cortex but, in the case of the striatum, very little is known about the molecular events associated with plasticity after lesions of this pathway. Using immunohistochemical techniques, we have examined the effects of cortical lesions induced either by aspiration of the frontoparietal cortex or by thermocoagulation of pial blood vessels on axonal and glial molecules associated with neuronal plasticity in the striatum. The growth associated protein GAP-43, a molecule present in axons and growth cones, decreased in the dorsolateral striatum after aspiration but not after thermocoagulatory lesions. In contrast, synaptophysin, a marker of synaptic vesicles, remained unchanged in the denervated striatum after both types of lesions. Immunostaining for basic fibroblast growth factor (bFGF) markedly decreased in striatal astrocytes after both lesions, despite an increased staining for glial fibrillary acidic protein (GFAP). The adhesion molecules tenascin, chondroitin sulfate proteoglycans, highly polysialylated neural cell adhesion molecule (PSA-NCAM), and laminin did not change significantly in the gray matter of the dorsolateral striatum after either type of lesion. These effects differed from those observed after partial denervation of the hippocampus and spinal cord, revealing marked regional differences in the response of axonal and glial proteins to afferent lesions. In addition, the results further indicate that cortical lesions have both similar and distinct consequences, depending on the procedure by which the lesions are induced, suggesting that cortical lesions associated with different types of pathology may differentially affect subcortical structures.
\end{abstract}

[Key words: GAP-43, synaptophysin, bFGF, laminin, PSA-NCAM, tenascin, chondroitin sulfate proteoglycan]

The striatum (caudate-putamen) plays a critical role in motor and cognitive behaviors (Evarts and Wise, 1984) and receives a massive excitatory input from the cerebral cortex (Somogyi et

\footnotetext{
Received Dec. 2, 1994; accepted Jan. 30, 1995

We thank Dr. G. Rougon (Luminy, France) for the gift of N-CAM and PSANCAM antibodies. Dr. S. Chang (U. Penn., Philadelphia) for the laminin antibody, and Dr. L. Benowitz (Harvard U., Boston) for the GAP-43 antibody. We are grateful to Drs. S. Erulkar, M. Murray, and M. DiFiglia for stimulating discussions and helpful suggestions on the manuscript and to C. Kuntz for help with the c-fos experiments. This work was supported by PHS Grant NS29230.

Correspondence should be addressed to M.-F. Chesselet, M.D., Ph.D., Department of Pharmacology, University of Pennsylvania, 3620 Hamilton Walk, Philadelphia, PA 19104-6084.

Copyright 1995 Society for Neuroscience 0270-6474/95/154429-20\$05.00/0
}

al. 1981). Loss of cortical inputs to the striatum occurs in pathological situations associated with cortical lesions, such as cerebral palsy and stroke. In addition this pathway is affected in neurodegenerative diseases such as Huntington's disease in which corticostriatal inputs degenerate (Cudknwicz and Kowall, 1990).

In experimental animals, lesions of corticostriatal neurons induce long-term changes in neurotransmitter gene expression in their target neurons of the striatum (Uhl et al., 1988; Somers and Beckstead, 1990; Salin and Chesselet, 1992, 1993). Previous studies have shown that these effects differ according to the procedure used to induce cortical degeneration. Acute cortical aspiration results in decreased expression of mRNAs encoding enkephalin and substance $P$, two neuropeptides present in distinct subsets of striatal efferent neurons (Uhl et al., 1988; Somers and Beckstead, 1990). In contrast, cortical lesions following ischemia induced by thermocoagulation of pial blood vessels induce long-lasting increases in enkephalin and tachykinin mRNA levels correlated with increases in the expression of the corresponding peptides (Salin and Chesselet, 1992, 1993).

Previous ultrastructural studies have suggested that aspiration lesions of the cerebral cortex induce a lasting loss of synaptic contacts on dendritic spines of striatal efferent neurons, the major site of corticostriatal synapses, with little evidence for compensatory sprouting from spared axons (Chen and Hillman, 1990). These results contrast with observations in other regions of the CNS after lesions of afferents. In particular, in the hippocampus, acute lesions of the entorhinal cortex are followed by sprouting from axons of the spared contralateral cortex and other hippocampal inputs (for review, see Cotman and Nadler, 1978). This is followed by reactive synaptogenesis, leading to recovery of $80 \%$ of synaptic contacts in the denervated dentate gyrus (Matthews et al., 1976). This compensatory axonal sprouting is accompanied by an increase in the growth-associated protein GAP-43 in growing axons (Benowitz et al., 1990; Masliah et al., 1991) and recovery of the vesicular protein synaptophysin (Masliah et al., 1991). Denervation of the dentate gyrus also causes changes in the immunohistochemical expression of molecules thought to regulate sprouting. Immunoreactivity for basic fibroblast growth factor (bFGF) increases in reactive astrocytes (Gomez-Pinilla et al., 1992) which also show increased immunostaining for the glial fibrillary acidic protein (GFAP) (Gage et al., 1988). Expression of the immature, highly polysialilated form of the neural cell adhesion molecule (PSA-NCAM) increases in the denervated region (Gage et al., 1988; Miller et al., 1994). Compensatory sprouting after lesions of afferent neurons has similarly been associated with increases in GAP- 43 and 
Table 1. Antibodies used in study

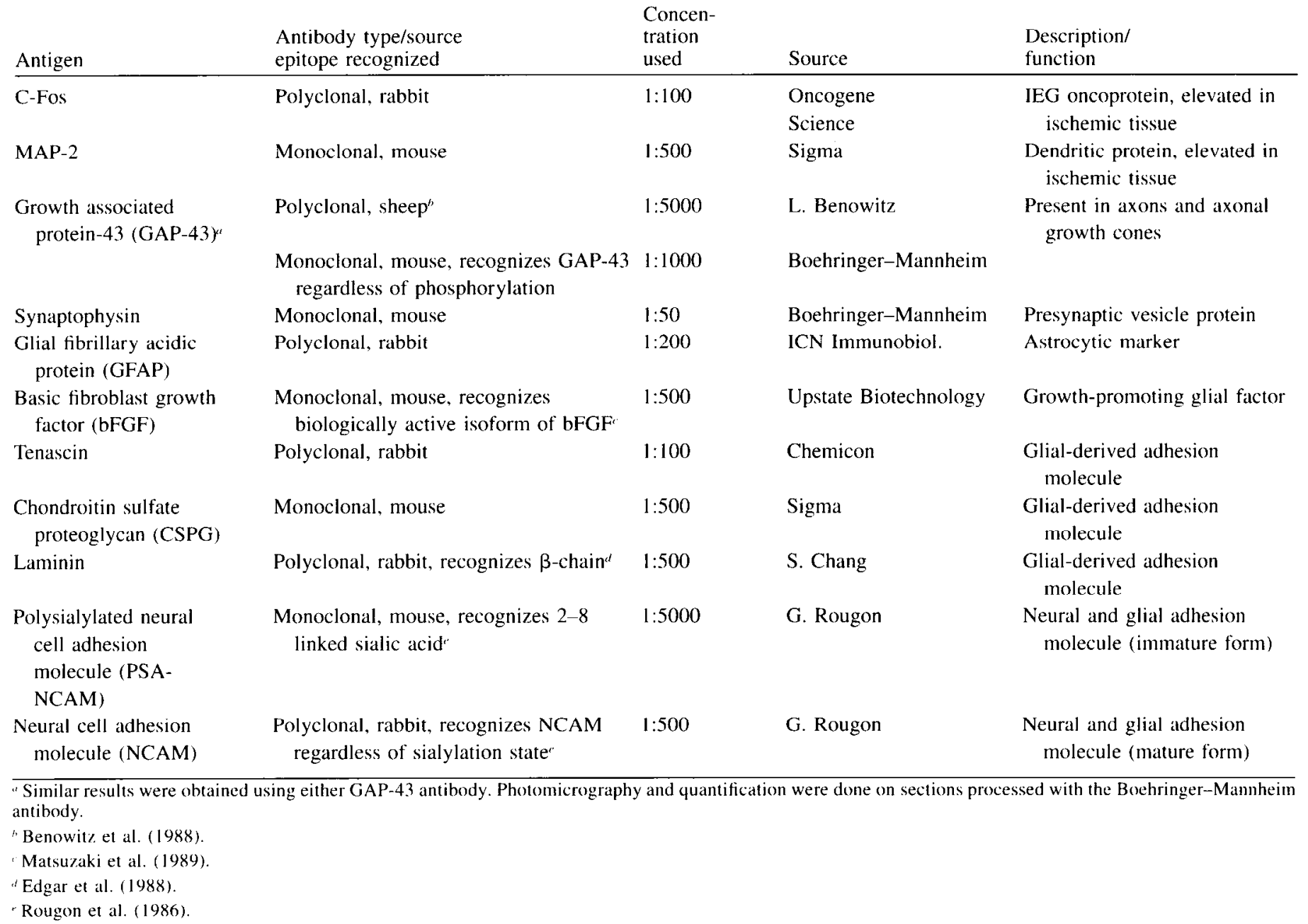

PSA-NCAM in the spinal cord (Battisti et al., 1993; Curtis et al., 1993; Chong et al., 1994).

It is not known whether similar changes in axonal- and glialderived molecules occur in the striatum, where cortical aspiration lesions do not induce compensatory axonal sprouting. Furthermore, it is unclear whether different types of cortical lesions that produce different effects on neurotransmitter expression in striatal neurons also induce different effects on striatal axons and glial cells. In the present study, we have examined the effects of both aspiration and thermocoagulatory lesions of the cerebral cortex on molecules associated with neuronal plasticity in the dorsolateral striatum. Immunoreactivity for the axonal markers GAP-43 and synaptophysin as well as for the glial-derived molecule bFGF and a panel of adhesion molecules was examined in cohorts of animals sacrificed at various time points after surgery.

\section{Materials and Methods}

Surgery and tissue preparation. Adult male (250-300 gm) SpragueDawley rats were deeply anesthetized with Equithesin $(1.0 \mathrm{ml} / 300 \mathrm{gm}$; prepared as per instruction of Janssen Laboratory) and their heads immobilized in a Kopf stereotaxic apparatus. Thermocoagulatory lesions have been extensively used to study the neurochemical effects of corticostriatal deafferentation and were performed as previously described (Dusticier et al., 1985; Errami and Nieoullon, 1986, 1988; Vuillet et al., 1989; Salin et al., 1990; Salin and Chesselet, 1992, 1993). Briefly, after removal of the skull, pial vessels of the left frontoparietal cortex $(+2$ to $-8 \mathrm{~mm}$ A.P. from bregma; Paxinos and Watson, 1986) were cauterized transdurally with rapid and light touches to the dura with a thermocoagulatory probe. Care was taken at all phases of the surgery to avoid tearing of the dura mater. Groups of animals $(n \geq 4)$ that received thermocoagulatory lesions were sacrificed $6 \mathrm{hr}, 1,3,5,7,12,16$, or 21 $\mathrm{d}$ after surgery. This includes the range of times during which sprouting has been observed in the hippocampus and spinal cord (Cotman and Nadler, 1978; Curtis et al., 1993; Murray, 1993).

Aspiration lesions were performed with a fire-polished glass pipette and the entire cortical area that degenerates after thermocoagulatory lesions was removed. Groups of animals that received aspiration lesions $(n \geq 4)$ were sacrificed 1, 7, 12, 16, or 21 d after surgery.

In sham-operated controls, the bone over the frontoparietal cortex was removed, but the vessels were not cauterized. Groups of sham-operated controls $(n=3)$ were sacrificed $6 \mathrm{hr}, 3,7,12$, or $21 \mathrm{~d}$ after surgery. In addition, groups of animals received only anesthesia $(n=5 \times 2$; separate groups for thermocoagulatory and aspiration lesions).

Animals were perfused with $4 \%$ paraformaldehyde in $0.1 \mathrm{~m}$ NaPBS $\mathrm{pH} 7.6$ at $4^{\circ} \mathrm{C}$. the brains were removed, cryoprotected in $30 \%$ sucrose overnight at $4^{\circ} \mathrm{C}$, and stored at $-70^{\circ} \mathrm{C}$. Ten micron sections were cut on a cryostat, thaw mounted on gelatin-coated slides, and stored at $-70^{\circ} \mathrm{C}$. Thirty-micrometer free-floating sections were also cut and processed in some experiments. These resulted in very similar patterns of labeling as "on slide" sections that were used for image analysis.

Antibodies. To obtain staining suitable for quantitative analysis, optimal concentrations of antibodies were determined in preliminary experiments using several dilutions and incubation times. The antibodies used in this study are listed and described in Table 1.

Immunohistochemistry. For most immunohistochemical procedures, 
sections were rinsed twice in $0.02 \mathrm{M}$ potassium phosphate buffered sa line (KPBS), and incubated in KPBS containing $0.1 \%$ Triton $\mathrm{X}-100$, and $3 \%$ normal goat serum or $0.5 \%$ BSA. Immunohistochemistry for neural cell adtesion molecule (N-CAM) and PSA-NCAM was carried out in $0.1 \mathrm{M}$ sodium phosphate-buffered saline (PBS). Triton X-100 was omitted for tenascin, chondroitin sulfate proteoglycan (CSPG), PSANCAM, and NCAM immunohistochemistry. Laminin immunohistochemistry was done both in the presence and absence of Triton X-100, which resulted in very similar patterns of immunoreactivity. In order to increase access of the anti-bFGF antibody to the cell nucleus, some sections were pretreated with $0.1 \mathrm{M} \mathrm{HCl}$ for $30 \mathrm{~min}$ at $60^{\circ} \mathrm{C}$.

The primary antibodies were applied to sections for $24-48 \mathrm{hr}$ at $4^{\circ} \mathrm{C}$ After rinses in buffer, mouse primary antibodies were incubated for 1 hr at room temperature with FITC-(for PSA-NCAM, NCAM, and double-label experiments), rhodamine- (for double label experiments), or peroxidase-conjugated goat anti-mouse secondary antibodies (Jackson Immunoresearch, West Grove, PA) at a concentration of 1:200. Sections incubated with rabbit primary antibodies were incubated for $1 \mathrm{hr}$ at room temperature with a biotinylated goat anti-rabbit antibody followed by the avidin-biotin complex (ABC) procedure (Vector Labs., Burlingame, CA) (Hsu et al., 1981). After three rinses in KPBS, these sections were reacted with diaminobenzidine tetrahydrochloride (DAB) $(0.05 \%)$ (Polysciences. Warrington, PA) and $0.003 \% \mathrm{H}_{2} \mathrm{O}_{2}$ in $0.1 \mathrm{M}$ Tris buffer at $\mathrm{pH}$ 7.4. Average incubation times for the antibodies used in this study were $10 \mathrm{~min}$, and care was taken to maintain this time rigorously constant for all sections processed within one single experiment. Double labeling for GFAP and bFGF was carried out by incubating the sections simultaneously with the two primary antibodies, and subsequently with rhodamine-conjugated anti-mouse, and FITC-conjugated anti-rabbil secondary antibodies.

To control for possible artifactual increases in nonspecific binding of antibodies in lesioned tissue, serially adjacent sections including the anatomical region of interest from lesioned animals were always processed in parallel in the presence and absence of primary antibody. Potential background staining obtained in the absence of the primary antibodies was considered nonspecific

lmage amalvsis. All quantifications were performed on $10 \mu \mathrm{m}$ cryostat-cut sections processed "on slide." Sections were examined under bright-field illumination with a Leitz Aristoplan microscope, and analyzed with a Morphon Image Analysis System (Salin and Chesselet, 1993). For quantitative analysis, the sections were viewed with a $4 \times$ objective, and the final magnification on the video monitor was $120 \times$. Control and lesioned brains were processed in parallel from perfusion through image analysis. In order to account for possible changes in immunoreactivity due to tissue shrinkage or swelling induced by the cortical lesion, striatal surface areas were measured. There was no difference in striatal surface area between lesioned and control animals at the time points examined. This is in agreement with previous observations after thermocoagulatory (Salin and Chesselet, 1992) and aspiration lesions (Chen and Hillman, 1990).

Relative levels of immunolabeling were only compared in sections processed in parallel within the same experiment with identical incubation times in the chromogen. Each experiment included sections from unlesioned and lesioned rats as well as immunohistochemical control sections from control and lesioned rats for background (nonspecific) staining determination. Measurements were made in the dorsolateral striatum ipsilateral to the lesion (see Fig. 5A), the area of maximal denervation (McGeorge and Faull, 1989). Because increases in immunoreactivity were sometimes found in a narrow band of striatal tissue immediately under the corpus callosum, this area was not included in the quantification to avoid masking potential changes in the dorsolateral striatum (Fig. 5A). This was done by drawing the limit of the quantified region on the callosal side $200 \mu \mathrm{m}$ from the inferior border of the corpus callosum. The outer limit of the striatal region in which measurements were made (referred to as "dorsolateral siriatum") was drawn as the mirror image of the curvature of the corpus callosum, starting $100 \mu \mathrm{m}$ lateral to the lateral corner of the subventrical zone (Fig. 5). The region delineated this way corresponded to the area of maximal denervation (McGeorge and Faull, 1989) and of marked increase in immunostaining for GFAP and OX-42, a marker of activated microglia (Zhang, Szele, and Chesselet, unpublished observations). Eventual large artifacts in staining or tears in the tissue were not included in the quantification.

For GAP-43, synaptophysin, and tenascin, a standard curve was constructed by interposing filters of known optical densities (Kodak), and the optical density of the DAB reaction product was measured as pre viously described by Masliah et al. (1990). The standard curve and all experimental values were generated using identical microscopic and camera conditions. Optical densities of the corresponding anatomical region in sections from control or lesioned rats not exposed to the primary antibody were subtracted from the experimental values in control or lesioned animals, respectively. Immunoreactivity to bFGF was quantified by counting positively labeled cells in the dorsolateral striatum. For all quantifications, two sections per rat were analyzed and averaged, and the resulting values used to calculate a mean \pm SEM per group $(n$ $=4-6$ ). A high level of reproducibility of labeling among animals was achieved with these procedures, as demonstrated by the small variability of the quantification data, particularly among unlesioned rats (see Results).

All statistical analyses were performed on absolute values with the STATVIEw computer package. Analysis of variance (ANOVA) was followed with either Dunnett's or the two-tailed Student's $t$ test corrected for multiple comparison, with differences considered nonsignificant (NS) when $p>0.05$. Comparisons were always made with corresponding unlesioned controls, rather than with the contralateral side. Indeed, in rats, the corticostriatal pathway is partially bilateral (McGeorge and Faull, 1987), and bilateral effects of cortical lesions on neurotransmitter expression have been observed previously (Salin and Chesselet, 1992, 1993). Data were expressed in percent of values obtained in the corresponding anesthetized controls, represented as " 0 hr" postlesion, for graphic representation only.

\section{Results}

\section{Cortical lesions}

Cortical lesions were produced either by acute aspiration of the frontoparictal cortex or by thermocoagulation of pial vessels overlying the frontoparietal cortex. As previously described ( $\mathrm{Er}$ rami and Nicoullon, 1986; Salin and Chesselet. 1992), thermocoagulation resulted in a progressive loss of neurons in the area under the cauterized vessels (Fig. 1 $A$ ). Compared to controls (Figs. 1 $A, 2 A$ ) and sham-operated rats (not shown), the cortical tissue was odematous $6 \mathrm{hr}$ (Fig. $2 B$ ). 1 and $3 \mathrm{~d}$ (Fig. 1A) after surgery, as can be seen by the increased height of the cortex. Pyknotic neurons (Fig. 2D, compared to control in $2 C$ ) were already observed $6 \mathrm{hr}$ postsurgery, but neuronal loss occurred progressively until 5-7 d after surgery, when the fronto-parietal cortex had atrophied to the level of the corpus callosum (Figs. $1 A, 7 A)$. In contrast, lesions by aspiration acutely remove cortical tissue; thus, the full depth of lesion is present immediately after surgery (Fig. 1 $A$ ). Lesions produced by aspiration of the frontoparietal cortex were of similar anterior/posterior and medial/lateral extent as thermocoagulatory lesions (Fig. $1 B$ ). The lesions induced by both procedures extended from $2 \mathrm{~mm}$ anterior to $8 \mathrm{~mm}$ posterior to bregma (Fig. $1 B$ ), had well-defined boundaries, and spared the medial agranular, medial frontal, and the cingulate cortices (see Figs. $1 B, 7 A$ ). The topographical extent of damage examined in Nissl-stained sections was very reproducible among animals after both types of lesion. Neither lesion produced decreases in striatal surface area or evidence of neuronal degeneration in the dorsolateral striatum in Nissl-stained sections at the time points examined in this study. Cortical lesions were not produced by sham operations alone (not shown). Nor were the effects in the striatum reported below observed after sham operations. Therefore, data were analyzed and represented in graphs with reference to anesthetized controls ( $0 \mathrm{hr}$ ).

\section{Immunolabeling in dorsolateral striatum}

Both types of lesions produced a maximal loss of cortical projections in the dorsolateral striatum (McGeorge and Faull, 1989), resulting in topographically restricted changes in glial cells and neurotransmitter expression (Salin and Chesselet, 1992, 1993; Zhang, Szele, and Chesselet, unpublished observations). Histo- 

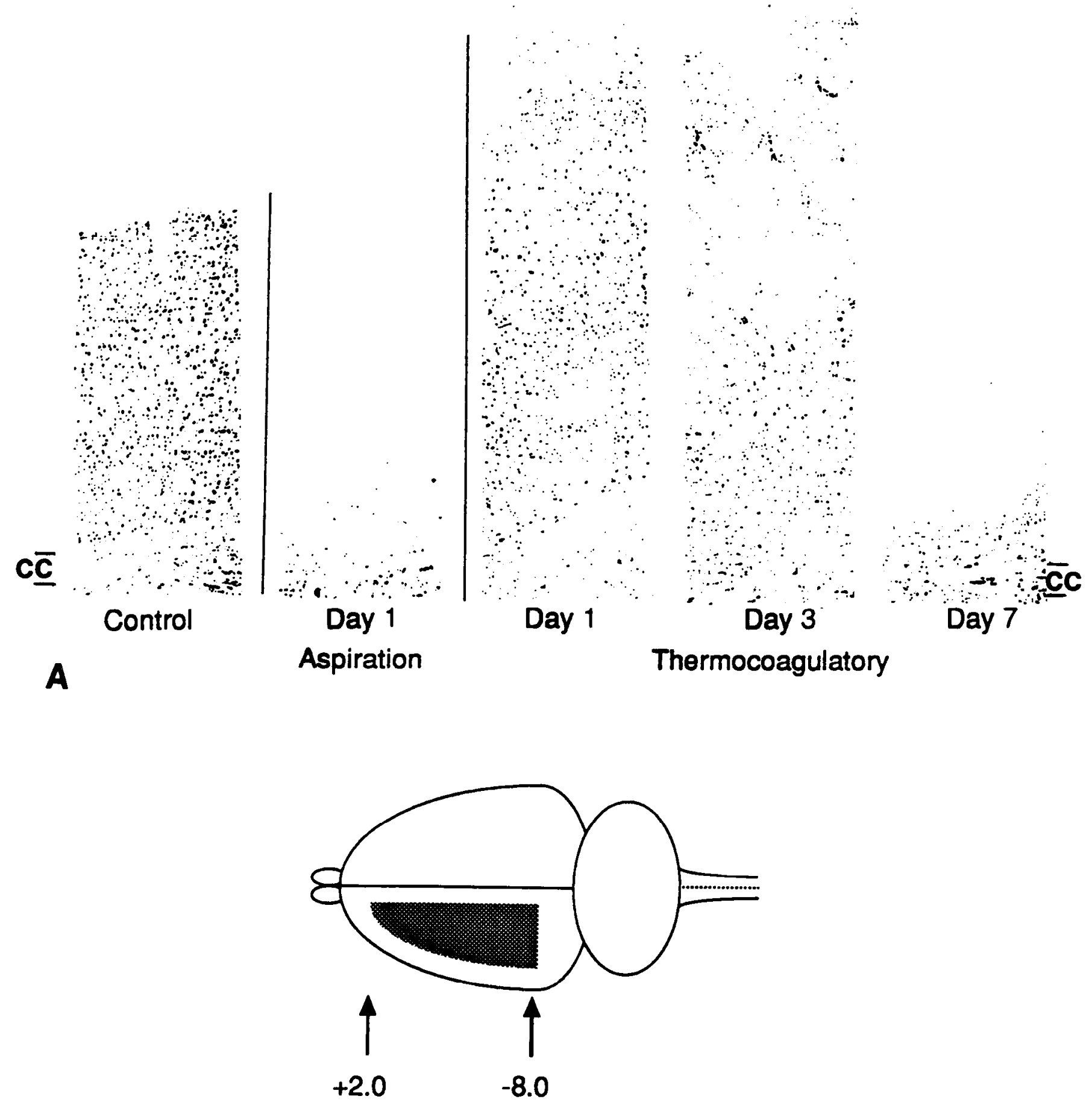

B

Figure 1. Time course and extent of aspiration and thermocoagulatory lesions of the frontoparietal cortex. A, Time course and dorsal/ventral extent of aspiration versus thermocoagulatory lesions compared to controls. Drawings were generated from Nissl-stained sections with a computerdriven image analysis system and show cell densities in coronal sections of the frontoparietal cortex before (control) and after lesions. $B$, Schematic of rat brain (dorsal view) showing the anterior/posterior $(+2.0$ to $-8.0 \mathrm{~mm}$ from bregma) and medial/lateral extent of both aspiration and thermocoagulatory lesions.

logical techniques were used in this study because they are particularly suitable for the detection of spatially restricted effects. Detailed analysis of immunohistochemical patterns was only done in the denervated dorsolateral striatum. This region is clearly separated from the cortical lesions by the corpus callos- um and does not show any signs of direct ischemic insult after thermocoagulation of pial blood vessels. This is illustrated in particular by the absence of induction of c-fos immunoreactivity in the dorsolateral striatum $6 \mathrm{hr}$ after thermocoagulatory lesions (Fig. $3 H$ ), whereas immunoreactivity for this immediate early 

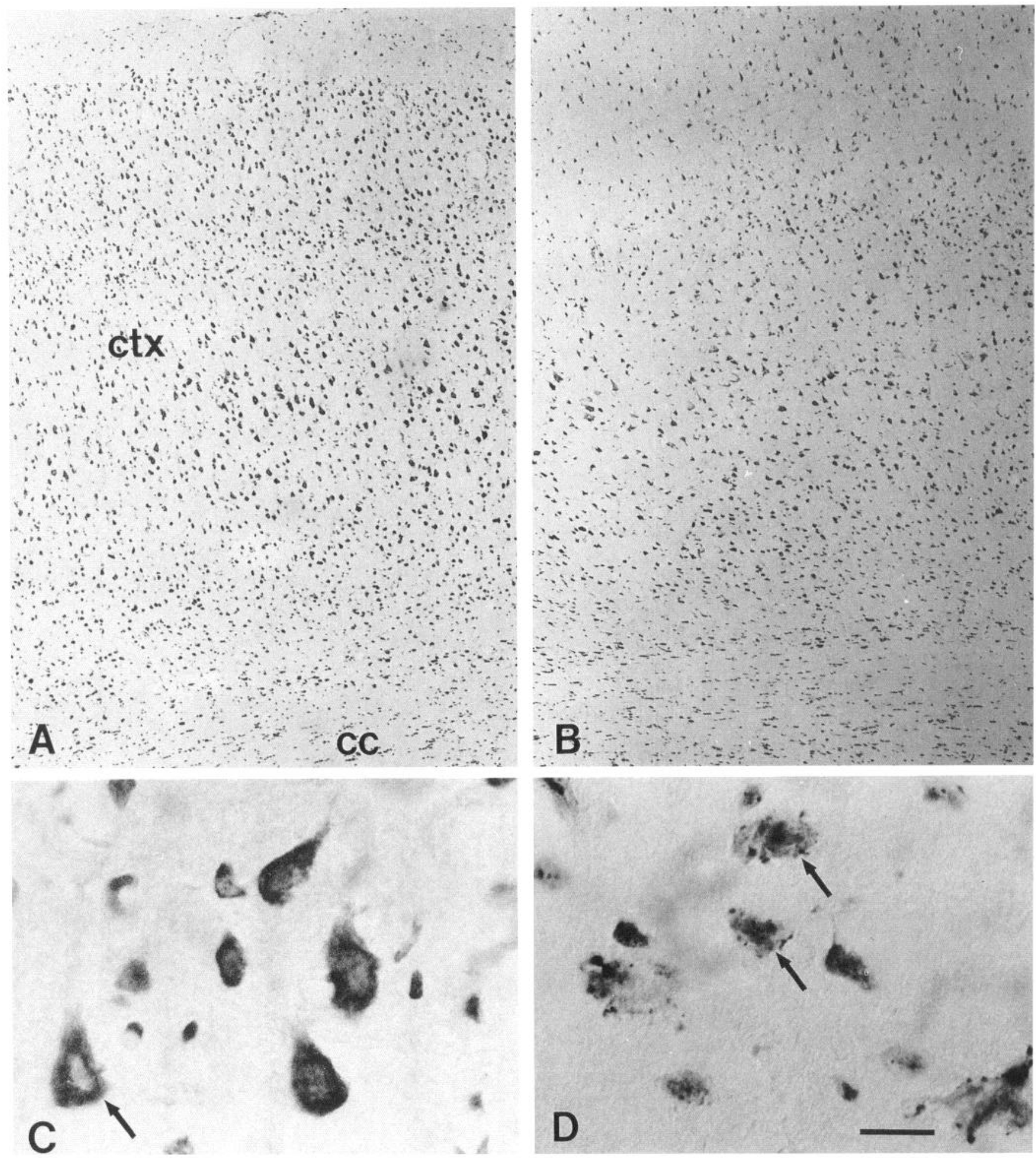

Figure 2. Nissl stain of cerebral cortex after thermocoagulatory lesions. $A$ and $B$, Low magnification showing cerebral cortex (ctx) and corpus callosum $(c c)$ in control rats $(A)$ and $6 \mathrm{hr}$ after thermocoagulation of pial vessels overlying the frontoparietal cortex $(B)$. $C$ and $D$, High magnification photomicrographs of pyramidal neurons in control $(C$, arrow $)$ and of degenerating pyknotic neurons in the cerebral cortex 6 hr after thermocoagulatory lesion $(D$, arrows $)$. Scale bar: $200 \mu \mathrm{m}(A$ and $B), 20 \mu \mathrm{m}(C$ and $D)$.

gene product increases markedly in the cerebral cortex at this time point (Fig. $3 F$ ). Similarly, microtubule-associated protein (MAP-2) immunoreactivity, an early marker of ischemic damage (Kitagawa et al., 1989) was markedly increased in the ischemic penumbra of the cerebral cortex (Fig. $3 B$ ) but not in the dener- vated dorsolateral striatum (Fig. 3D), $3 \mathrm{~d}$ after thermocoagulatory lesions. Furthermore, nonspecific increases in immunostaining were not observed in the dorsolateral striatum in contrast to the immediate border of the lesion (see Figs. $6 C, 11 C$ ).

GAP-43 and synaptophysin immunoreactivity. GAP-43 is 

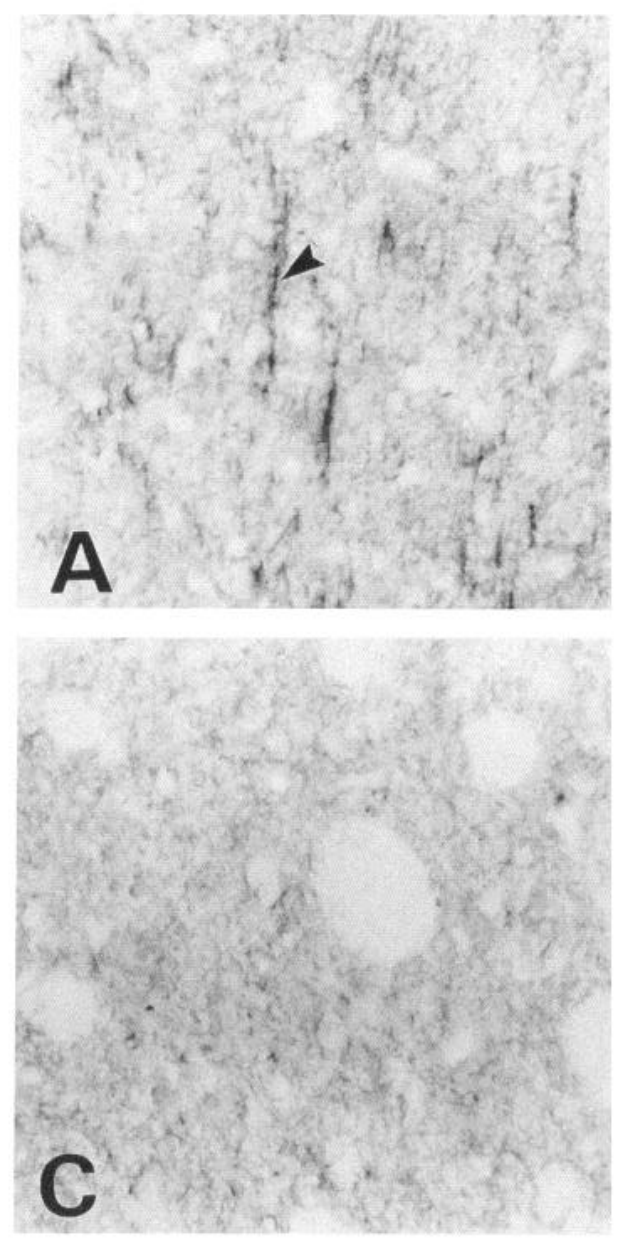

Figure 3. MAP-2 and c-fos immunohistochemistry. $A$, and $B$, MAP-2 immunoreactivity in dendrites (arrowheads) in the cortex of a control rat $(A)$ and $3 \mathrm{~d}$ after thermocoagulatory lesion $(B)$. Note paucity of immunoreactivity in lesioned cortex (asterisk in B) in contrast to the strong immunoreactivity in dendrites and cell bodies (arrow) in the penumbra (left side of $B$ ). $C$, and $D$, MAP-2 immunoreactivity in the dorsolateral striatum of a control rat $(C)$ and $3 \mathrm{~d}$ after thermocoagulatory lesion $(D) . E$ and $F$, c-fos immunoreactivity is below the level of detection in cortex of a control rat $(E)$ but is strong in cortical cells (arrow) in the ischemic penumbra $6 \mathrm{hr}$ after thermocoagulatory cortical lesion $(F)$. $G$ and $H$, c-fos immunoreactivity is below the level of detection in the dorsolateral striatum of both control rat $(G)$ and $6 \mathrm{hr}$ after thermocoagulatory lesion of the frontoparietal cortex $(H)$. Scale bar, $50 \mu \mathrm{m}$.

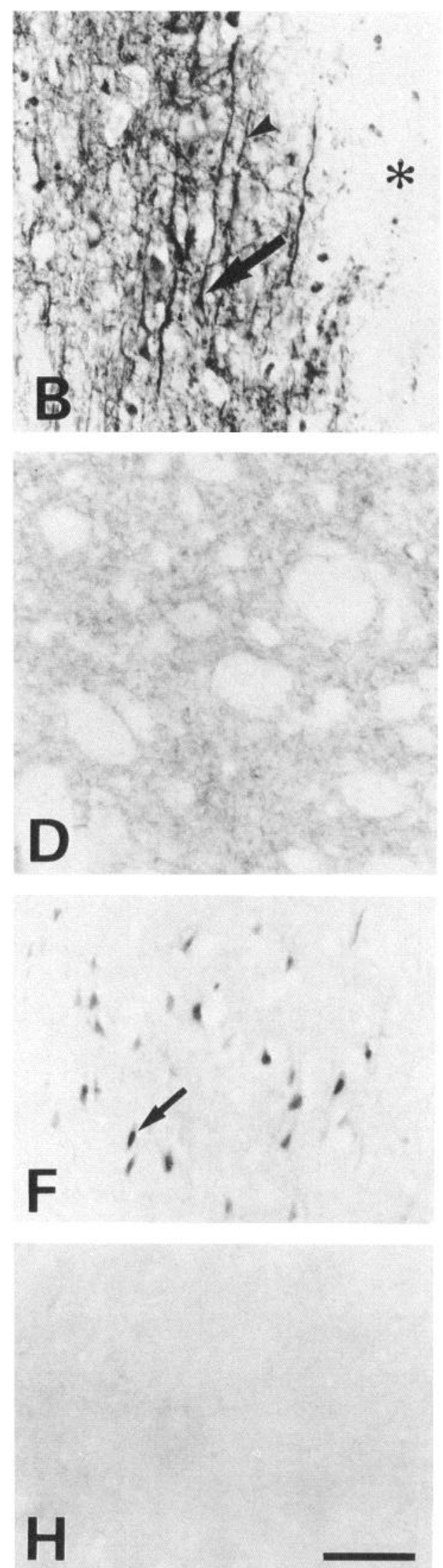
found in adult axons; however, its expression is increased in growth cones and growing axons (Jacobson et al., 1986; Benowitz et al., 1988; DiFiglia et al., 1990). As previously reported (DiFiglia et al., 1990), specific immunolabeling for GAP-43 was detectable in the striatum of control rats (Fig. $4 A$ ) with a higher level of immunoreactivity in the medial part of the striatum (ventricular, right edge of Fig. $4 A$ ) than in its dorsolateral part (Szele et al., 1994). In agreement with previous reports (DiГiglia et al., 1990), some punctate labeling was occasionally seen, but the labeling was mostly diffuse (Fig. 4A,C). Some positively labeled fibers were observed in the corpus callosum bordering the striatum (Fig. 4A). No specific labeling was observed in sections processed in the absence of primary antibody (Fig. 4B).

Immunoreactivity to GAP-43 was slightly lower than in controls in dorsolateral striatum $6 \mathrm{hr}$ and $1 \mathrm{~d}$ after thermocoagulatory lesions, but this decrease was not significant (Fig. $5 B$ ) $(F$ $=0.5$ ). In contrast, immunoreactivity to GAP-43 was markedly decreased in the dorsolateral striatum 7 to $21 \mathrm{~d}$ after aspiration lesions $(F=12.5, p=0.002$ ) (Figs. $4 E-G, 5 C)$. This effect was regionally specific, GAP-43 labeling being similar to control levels in the medial and ventral parts of the striatum (Fig. $4 E, G$ ). A transient increase in GAP-43 immunoreactivity could be seen immediately under the corpus callosum after aspiration (Fig. 4E) and thermocoagulatory lesions. Because of its close proximity to the lesion, however, this effect is difficult to interpret and will require further analysis at the ultrastructural level.

The major difference in the effects of thermocoagulatory versus aspiration lesions of the cerebral cortex on GAP-43 immunoreactivity in the dorsolateral striatum prompted us to determine whether the two lesions also induced differential effects on the expression of a marker of synaptic vesicles, synaptophysin, in sections from the same rats.

\section{Sinaptophysin immunoreactivity}

In control animals, specific labeling for synaptophysin was rather uniform in the dorsolateral striatum (Fig. 6A). No specific labeling was observed in sections processed in the absence of primary antibody (Fig. 6B). Synaptophysin immunoreactivity was largely unchanged compared to controls in the dorsolateral striatum after both aspiration (Fig. $7 B)(F-1.2, \mathrm{NS})$ and ther mocoagulatory lesions (Figs. $6 C-F, 7 A$ ). However, the ANOVA was significant after thermocoagulatory lesions $(F=5.6, p=$ 0.02 ) because a small and transient decrease was detected at 16 $\mathrm{d}$ (Fig. 7A). In some cases, a slight increase in immunostaining was seen immediately under the corpus callosum (Fig. 6C), but this effect was small and not consistent from animal to animal.

\section{GFAP and bFGF immunoreactivity}

$G F A P$. A general response of astrocytes to afferent lesions in the CNS is an increased expression of GFAP, an astrocyte-specific intermediate filament protein (Bignami et al., 1972; Reier, 1986). As expected (Herrera and Cuello, 1992; Pasinetti et al., 1993), immunolabeling for GFAP was weak in the striatum in control rats (Fig. 8B), but increased rapidly in the dorsolateral striatum after both types of lesions. The topography of increase in GFAP immunostaining $5 \mathrm{~d}$ after a thermocoagulatory lesion is illustrated in Fig. 8A. In the striatum, the increase in immunostaining (large arrow) was limited to the dorsolateral striatum, in which maximal loss of cortical inputs occurs (McGeorge and Faull, 1989). In addition, strong immunolabelling for GFAP was seen in the corpus callosum (arrowheads), and in the cortex, bordering the lesioned area. After lesion, most astrocytes in the dorsolateral striatum exhibited reactive morphology character ized by an enlarged cell body and shortened, swollen processes (Fig. 8C).

$b F G F$. Previous work has shown that several different bFGF antibodies, including the one used in this study, detect bFGF immunoreactivity in the nuclei of astrocytes (Woodward et al., 1992; Gomez-Pinilla et al., 1994; Kostyk et al., 1994). In agreement with these observations, strong immunostaining for bFGF was observed in the nucleus of a large number of cells in the striatum of controls (Fig. $9 A, E$ ). Double-lahel experiments indicated that in all areas examined including the striatum bFGFpositive cells were also GFAP positive and that most, but not all, astrocytes expressed bFGF. This is illustrated in the frontal cortex adjacent to the lesion (Fig. $8 D, E$ ) in which increased labeling for both GFAP and bFGF greatly facilitates their detection in double-label experiments. Acid pretreatment of sections did not change the pattern but increased the intensity of bFGF immunolabeling. Therefore, sections processed this way were used for quantitative analysis.

Both thermocoagulatory and aspiration cortical lesions induced a marked decrease in bFGF immunoreactivity in the dorsolateral striatum (Figs. 9, 10). The time course of the effect after thermocoagulatory lesions is shown in Fig. $9 B-D$. Compared to controls (Fig. 9A,E), the decreasc was alrcady obscrved $1 \mathrm{~d}$ after surgery (Fig. 9B). By $7 \mathrm{~d}$ after lesion, very few cells were bFGF immunoreactive in the dorsolateral striatum. The marked decrease in bFGF labeling is illustrated in Figure $9 C$. showing a large field of the dorsolateral striatum in which no labeled cells could be seen. bFGF immunoreactivity continued to be low in dorsolateral striatum at $16 \mathrm{~d}$, but the decrease was no longer significant compared to controls by $21 \mathrm{~d}$ postlesion (Fig. 9D). Similarly, after aspiration lesions, bFGF immunoreactivity was virtually absent from the dorsolateral striatum 7 d postsurgery (Fig. $9 F$ ) compared to the corresponding controls (Fig. 9E). The time course of the decrease after aspiration lesion (Fig. 10: $F=14.8, p<0.0001$ ) was similar to the time course of decrease after thermocoagulatory lesions. The decrease observed after both lesions was regionally specific, labeling being still present in the medial and ventral striatum, and in the contralateral cerebral cortex (not shown).

\section{Adhesion molecules}

Several adhesion molecules associated with the extracellular matrix, neurons, or reactive astrocytes are known to play a role in the regulation of neurite outgrowth in vitro, and have been shown to increase in response to afferent lesions or other types of brain injury (McKeon et al., 1991; Laywell et al., 1992; Le Gal La Salle et al., 1992; Letourneau et al., 1994; Miller et al., 1994; Muller et al., 1994). This raises the possibility that these molecules could also play a role in regulating compensatory axonal sprouting in vivo. To further examine possible differences in the effects of aspiration and thermocoagulatory lesions of cerebral cortex on the factors that may influence axonal sprouting in the striatum, we have examined immunolabeling for tenascin, chondroitin sulfate proteoglycans, laminin, and polysialylated NCAM in the dorsolateral striatum after both types of lesions.

Tenascin. The glial-derived adhesion molecule tenascin was examined because it has both inhibitory and facilitatory effects on axonal elongation in vitro (Faissner and Kruse; 1990); Lochter et al., 1991), and may provide a boundary for axonal growth during development and after neuronal injury (Steindler et al., 


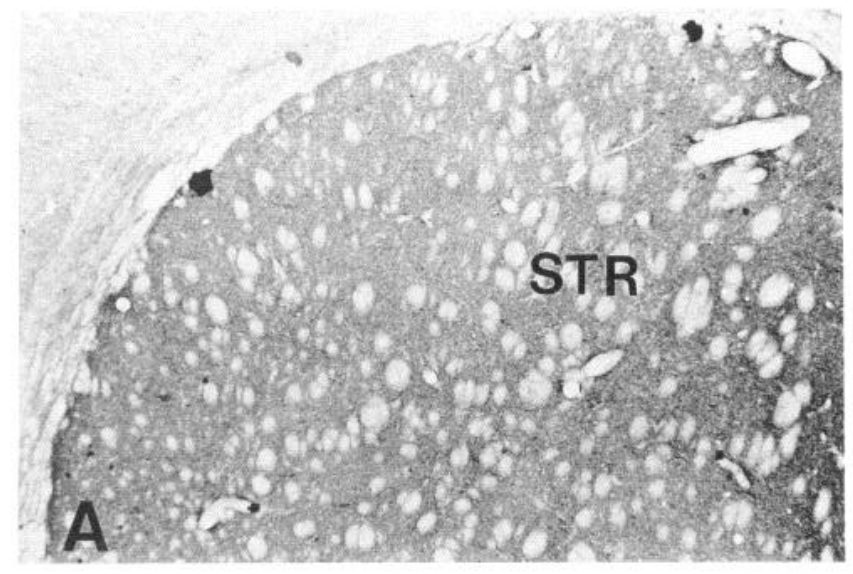

\section{B}
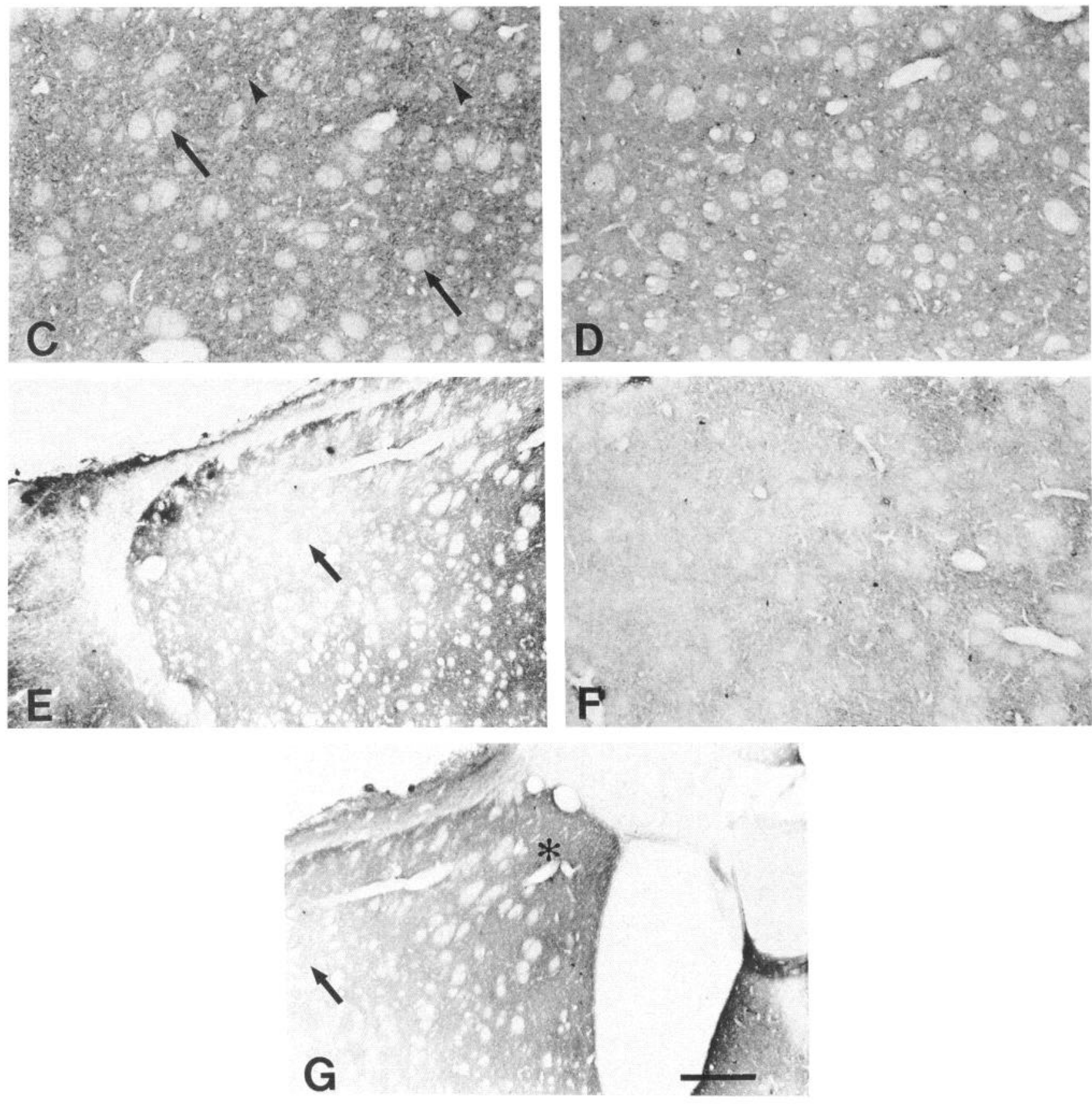

a

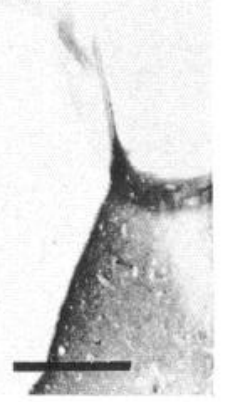






A

Thermocoagulatory

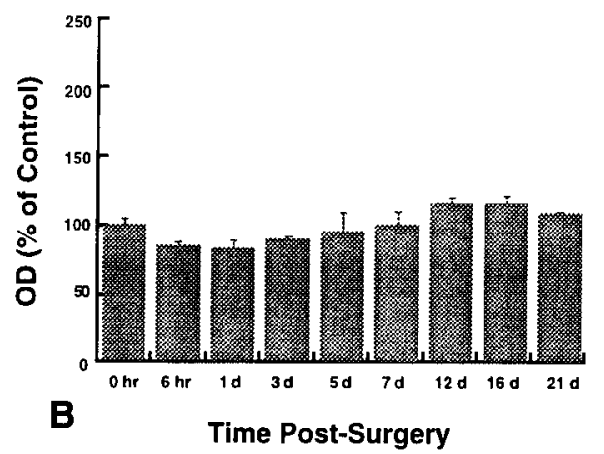

Aspiration

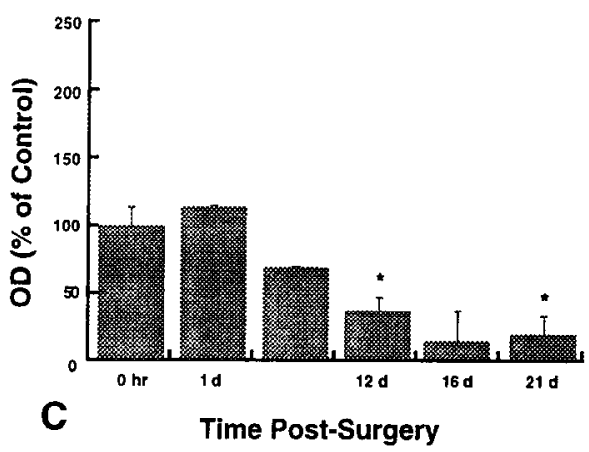

Figure 5. A, Schematic of frontal section of rat brain at the level of the striatum: $A L$. area lesioned: SC STR. subcallosal striatum; $D L S T R$, dorsolateral striatum; CTX, cerebral cortex; $C C$. corpus callosum: $L V$. lateral ventricle. $B$ and $C$, Levels of GAP-43 immunoreactivity in the dorsolateral striatum after unilateral thermocoagulatory $(B)$ or aspiration lesions $(C)$ of the cortex. $0 \mathrm{hr}=$ controls. Absolute values were $0.0180 \pm 0.003$ at $0 \mathrm{hr}$ and $0.0068 \pm$ 0.002 at $12 \mathrm{~d}$ after aspiration lesions (optical density; arbitrary units). Significance was tested with ANOVA and a post hoc two-tailed Student's t test with Bonferroni's correction for multiple comparisons. *, $p \leq 0.05$ compared to controls.
1989; McKeon et al., 1991; Laywell et al., 1992). Diffuse immunolabeling for tenascin was observed in the neuropil of the striatum in control rats (Fig. $11 A$ ). Tenascin immunoreactivity was also observed in the corpus callosum of controls (Figs. 11A, $13 E$ ). No specific labeling was detected when the primary antibody was omitted (Fig. $11 B$ ). Although a band of immunoreactivity could be observed immediately under the corpus callosum after thermocoagulatory lesions (Fig. 1 1 C), no significant differences from control were observed in the rest of the dorsolateral striatum after either thermocoagulatory lesions (Figs. $11 C, D ; 12)(F=0.9$, NS) or aspiration lesions (not shown).

In contrast to the lack of changes observed in the gray matter of the dorsolateral striatum, tenascin immunoreactivity was markedly increased in corpus callosum from $6 \mathrm{hr}$ (Figs. $11 \mathrm{C}$, $13 F$ ) to $5 \mathrm{~d}$ after thermocoagulatory cortical lesions compared to controls (Figs. 11A, 13E). From 5 (Fig. 13B) to $12 \mathrm{~d}$ (Fig. $13 C$ ) postsurgery, tenascin immunoreactivity appeared in the corticofugal fiber tracts crossing through the striatum that are unlabeled in controls (Fig. 13A). This effect coincided with the appearance of cysts in these myelinated fiber tracts likely cor- responding to degenerated axons (Fig. 13B, arrowheads), and was no longer observed $21 \mathrm{~d}$ pustsurgery (Fig. 13D). After aspiration lesions, tenascin immunoreactivity was rapidly ( $1 \mathrm{~d}$ ) increased in the corpus callosum and remained elevated for a longer time $(21 \mathrm{~d})$ than after thermocoagulatory lesions (not shown). Increases in tenascin were also seen in the corticofugal fiber tracts of the striatum after aspiration lesion (not shown).

Chondroitin sulfate proteoglycans. Chondroitin sulfate proteoglycans have also been shown to contribute to pattern formation by providing a negative cue for axonal growth (Brittis and Silver, 1992). Weak immunoreactivity to chondroitin sulfate proteoglycan (CSPG) was observed in the corpus callosum of controls (Fig. 13G), but no specific labeling was detected in the dorsolateral striatum (not shown). Increases in CSPG immunolabeling were observed in the corpus callosum after thermocoagulatory lesions but only $6 \mathrm{hr}$ to $3 \mathrm{~d}$ after surgery (Fig. 13H).

Laminin. In contrast to CSPG, laminin has been shown to be a potent stimulator of neurite outgrowth (Rivas et al., 1992). It is found in the basal lamina of blood vessels as well as in the extracellular matrix of brain areas associated with high levels of

Figure 4. GAP-43 immunohistochemistry. A, GAP-43 immunoreactivity in the striatum (STR) of a control rat. $B$. Striatal section from a control animal processed in the absence of primary antibody. $C$. Higher power magnification of GAP-43 immunoreactivity in the dorsolateral striatum of a control rat. Note the absence of labeling in the corticostriate fiber tracts (arrows) and in cell bodies (arrowheads). $D$. GAP-43 immunoreactivity in the dorsolateral striatum $12 \mathrm{~d}$ after thermocoagulatory lesion of the frontoparietal cortex. $E$ and $F$. Low $(E)$ and high $(F)$ power photomicrographs of GAP-43 immunoreactivity $16 \mathrm{~d}$ after aspiration lesion of the frontoparietal cortex. $G$, Decreased immunoreactivity in the dorsolateral striatum contrasts with normal levels of GAP-43 in the medial striatum (asterisk) (arrow corresponds to arrow in $E$ ). Scale bar: $500 \mu \mathrm{m}(A, B, E$, and $G$ ). $200 \mu \mathrm{m}(C, D$, and $F)$. 

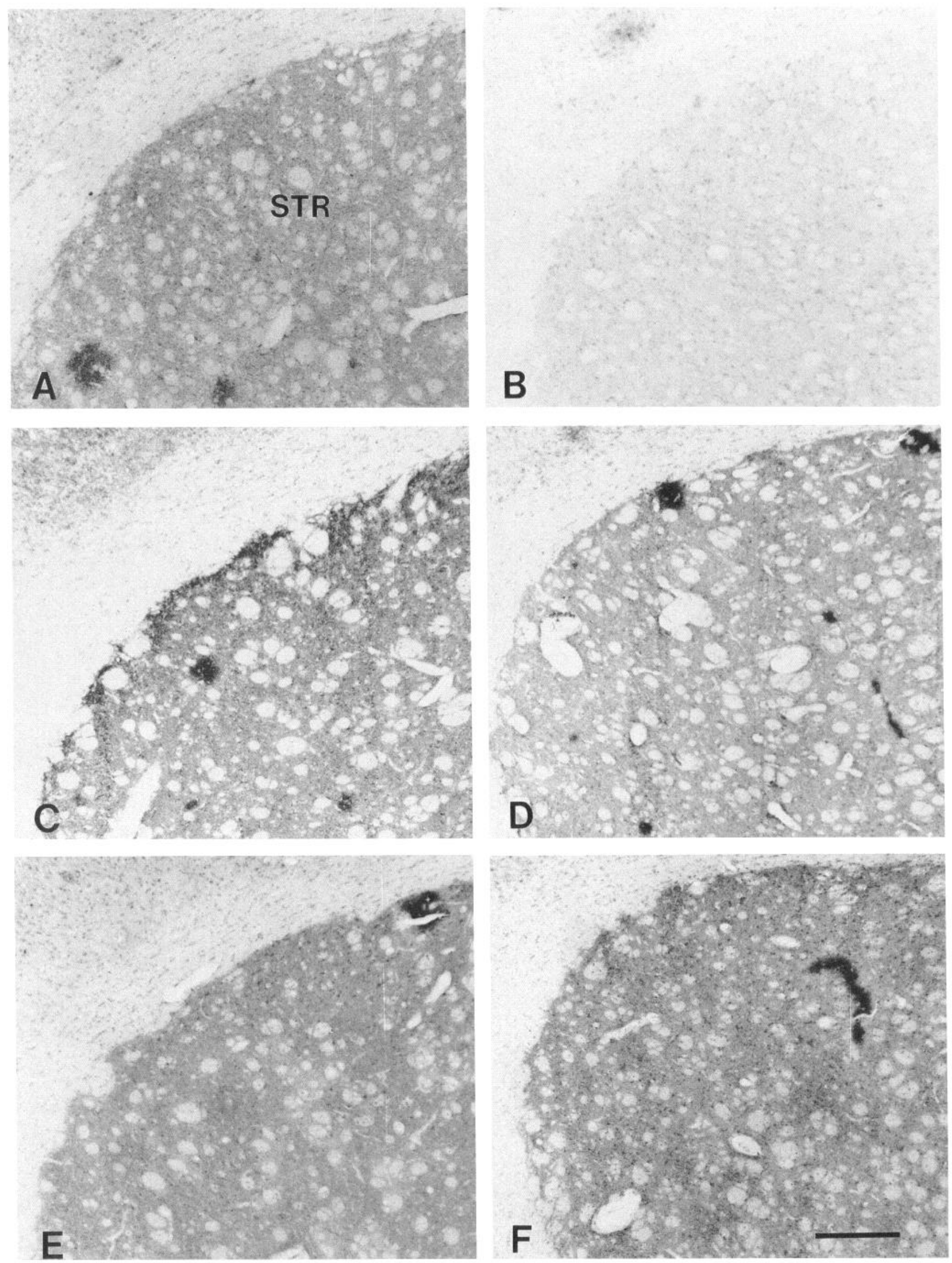
Thermocoagulatory

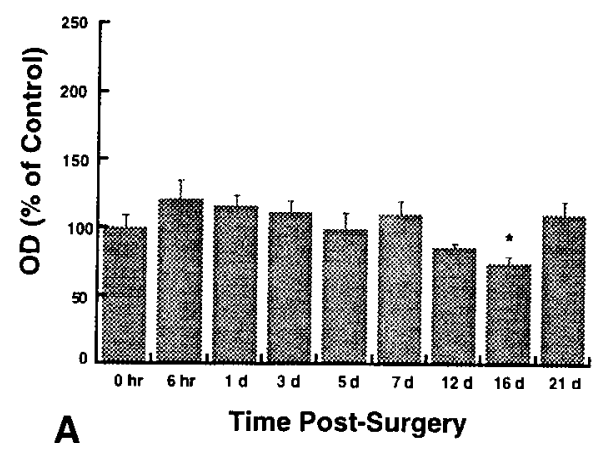

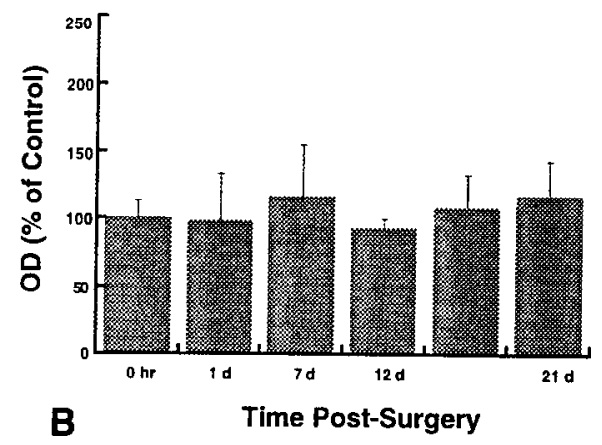

Figure 7. Levels of synaptophysin immunoreactivity in the dorsolateral striatum after unilateral thermocoagulatory $(A)$ or aspiration $(B)$ lesions of the frontoparietal cortex. Significance was tested for with ANOVA and a post hoc two-tailed Student's $t$ test with Bonferroni's correction for multiple comparisons. *, $p \leq 0.05$ compared to controls. plasticity in the adult (Liesi et al., 1984; Liesi, 1985). In controls, laminin immunoreactivity was detected in the basal lamina of blood vessels in the corpus callosum and the dorsolateral striatum (Fig. 14A,C). Omission of the anti-laminin antibody resulted in complete lack of immunolabeling (Fig. 14D). Laminin immunoreactivity was increased in the vasculature of the corpus callosum $6 \mathrm{hr}$ to $5 \mathrm{~d}$ after thermocoagulatory cortical lesions (Fig. 14B) but did not increase in the vasculature or neuropil of the striatum at any point after thermocoagulatory lesions (Fig. $14 E$ ). Similarly, laminin immunoreactivity was not increased in the neuropil of the striatum after aspiration lesions (Fig. 14F). However, neovascularization was observed in the dorsolateral striatum $7 \mathrm{~d}$ (Fig. 14F) after aspiration lesions.

PSA-NCAM. High levels of polysialic acids (PSA) are associated with NC $\triangle \mathrm{M}$ throughout the brain during development but only in restricted areas in the adult brain (Chuong and Edelman, 1984; Aaron and Chesselet, 1989; Bonfanti et al., 1992; Szele et al., 1994). PSA-NCAM is important for axonal morphogenesis (Doherty et al., 1990; Landmesser et al., 1990), and is expressed by glial cells in models of brain injury, and by neurons after partial denervation of the hippocampus (Le Gal La Salle et al., 1992; Miller et al., 1994). In the present study, NCAM and PSA-NCAM were detected with fluorescence immunohistochemistry because, in our experience, this technique provides superior sensitivity for the detection of low levels of expression of these membrane-bound antigens at the light microscopic level (Aaron and Chesselt, 1989; Szele et al., 1994). As previously reported (Aaron and Chesselet, 1989; Szele et al., 1994), immunoreactivity to PSA-NCAM was undetectable in the dorsolateral striatum of unlesioned adult rats (Fig. 14G). No re-expression of PSA-NCAM was detected in the dorsolateral striatum or corpus callosum at $1 \mathrm{~d}$ (Fig. $14 H$ ) and up to $21 \mathrm{~d}$ after thermocoagulatory or aspiration lesions (not shown). This was not due to a lack of expression of the mature form of NCAM, since, as previously reported (Aaron and Chesselet, 1989), immunolabeling for NCAM was strong in the dorsolateral striatum and remained unchanged both in the corpus callosum and in the striatum up to $21 \mathrm{~d}$ after surgery (not shown).

\section{Discussion}

A battery of molecules associated with neuronal plasticity was examined in the striatum after cortical lesions induced either by acute aspiration or thermocoagulation of pial blood vessels. The results revealed both differences and similarities in the effects of cortical deafferentation induced by these distinct procedures (Table 2). Although the lesions differentially affected the expression of the axonal marker GAP-43 in the denervated dursolateral striatum, they both produced a robust decrease in immunostaining for the growth-promoting factor bFGF and little changes in the expression of a panel of adhesion molecules that

\footnotetext{
Figure 8. GFAP and bFGF immunohistochemistry. A, GFAP immunoreactivity in the dorsolateral caudate putamen (cp) (large arrow), the corpus callosum (cc) subjacent to the lesion, and the cerebral cortex $(c x) 5 \mathrm{~d}$ after thermocoagulatory lesions of the frontoparietal cortex. Note the increased labeling in these areas compared with the low level of immunostaining seen in the medial caudate-putamen (small arrow) and the septum (sp). $B$, Higher magnification photomicrograph of a typical astrocyte in the striatum of a control rat. Arrowheads point to a long thin process emanating from the small cell body. $C$. Typical reactive astrocyte in the denervated dorsolateral striatum of a lesioned animal (same magnification as in $B$ ). $D$ and $E$, GFAP and bFGF double immunofluorescence $5 \mathrm{~d}$ after thermocoagulatory lesion. Photomicrograph of the same field in the frontoparietal cortex adjacent to the lesion showing immunoreactivity to GFAP $(D)$ and bFGF $(E)$. Arrows point to some examples of colocalized GFAP and bFGF immunoreactivity. Scale bars: $800 \mu \mathrm{m}(A), 8 \mu \mathrm{m}(B$ and $C), 40 \mu \mathrm{m}(D$ and $E)$.
}

Figure 9. bFGF immunoreactivity. $A$ and $E$, bFGF immunoreactivity in sections from control rats processed in parallel with sections from rats with thermocoagulatory and aspiration lesions of the frontoparietal cortex, respectively. $B-D$, bFGF immunoreactivity $\mathrm{l}(B), 7(C)$, and $21 \mathrm{~d}(D)$ after thermocoagulatory lesions of the frontoparietal cortex. $F$. bFGF immunoreactivity $7 \mathrm{~d}$ after aspiration lesion of the frontoparietal cortex. Scale bar, $40 \mu \mathrm{m}$.

Figure 6. Synaptophysin immunoreactivity. $A$, Synaptophysin immunoreactivity in the striatum (str) of a control rat. $B$. Striatal section processed in the absence of primary antibody. $C-F$. Synaptophysin immunoreactivity in the dorsolateral striatum $3(C), 7(D), 12(E)$, and $21 \mathrm{~d}(F)$ after thermocoagulatory lesions of the fontoparietal cortex. Note that patches of very dense staining are artifactual. Scale bar, $300 \mu \mathrm{m}$. 

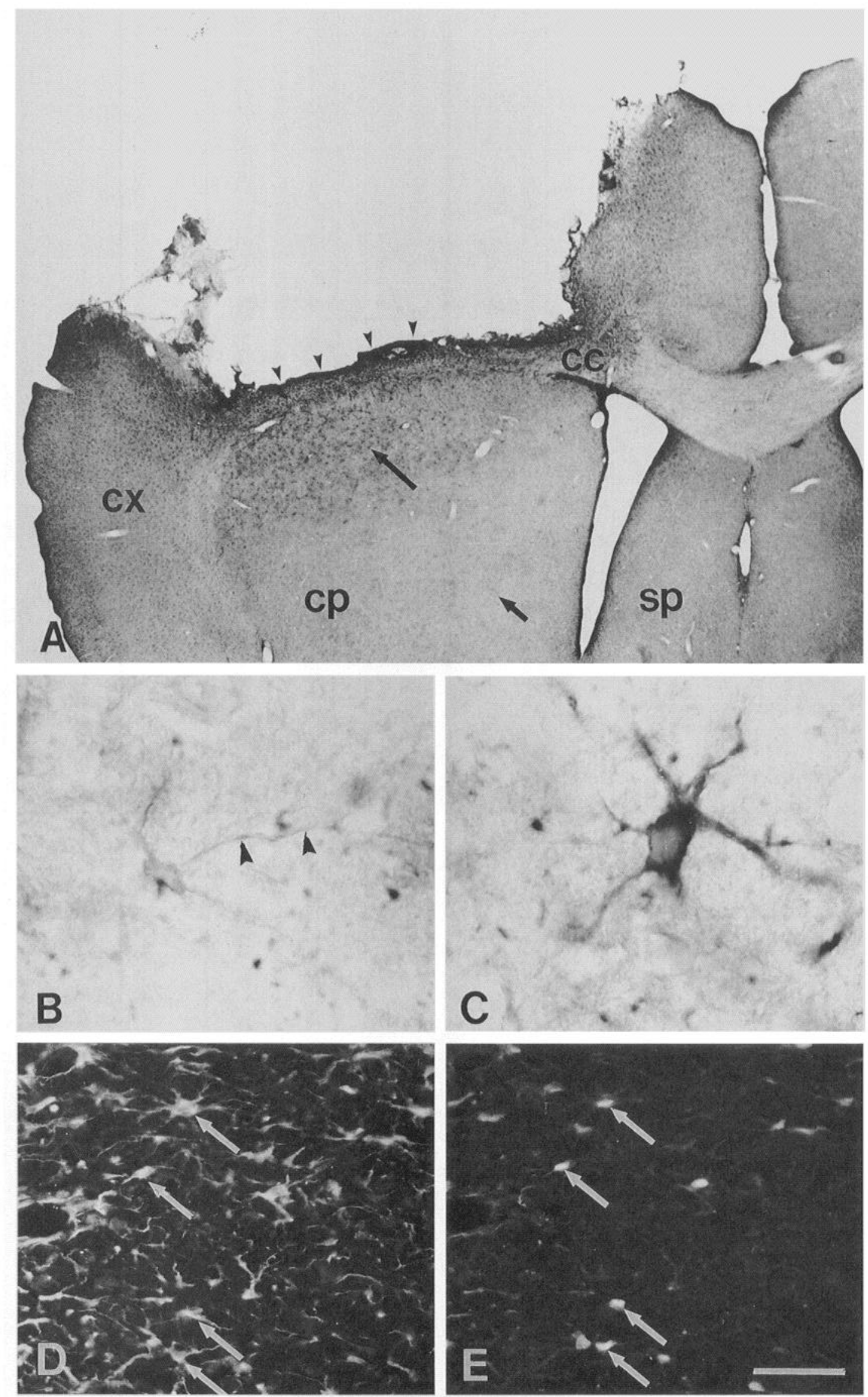





Figure 10. Number of bFGF immunolabeled cells in the dorsolateral striatum after aspiration lesions of the frontoparietal cortex. Significance was tested with ANOVA and Dunnett's post hoc test. *, $p \leq 0.05 ; * *, p \leq 0.01$; compared to controls.

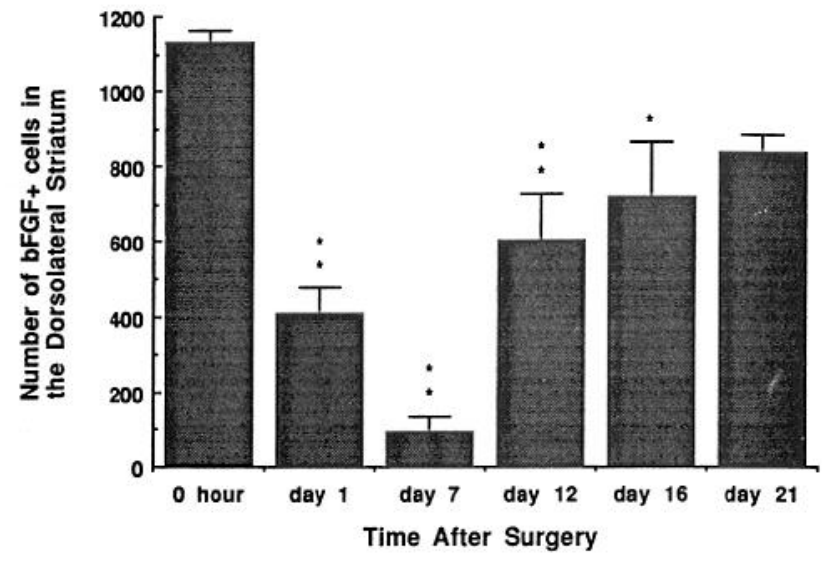

may also play a role in neurite outgrowth. The effects induced by both types of striatal denervation differed from those observed in the hippocampus after lesions of the entorhinal cortex, and also differed from the effects of direct injuries to gray matter. This provides evidence that axonal and glial responses to deafferenting lesions are regionally specific, and that different types of lesions induce molecular responses that may result in different levels of neuronal plasticity.

\section{Immunoreactivity to GAP-43 in the denervated striatum}

The prolonged decrease in GAP-43 observed in the dorsolateral striatum after aspiration lesions is in contrast with observations
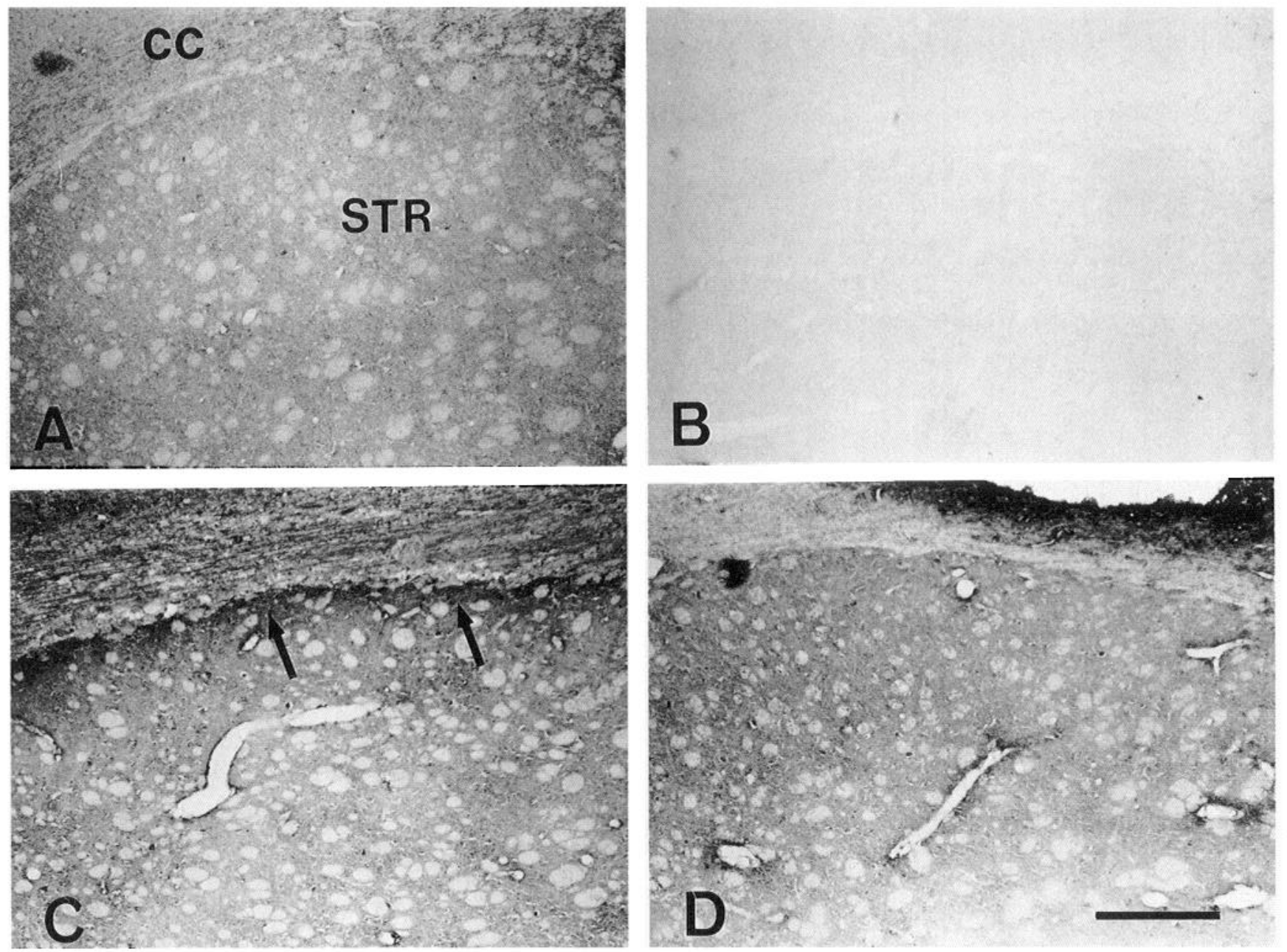

Figure 11. Tenascin immunoreactivity. A, Tenascin immunoreactivity in the striatum $(S T R)$ and corpus callosum $(c c)$ of a control rat. B, Striatal sections processed in the absence of primary antibody showing specificity of immunolabel in $A$. $C$ and $D$, Tenascin immunoreactivity $6 \mathrm{hr}(C)$ and $12 \mathrm{~d}(D)$ after thermocoagulatory lesions of the frontoparietal cortex. Note increased immunoreactivity in the subcallosal striatum (arrows) and corpus callosum in $C$. Scale bar, $400 \mu \mathrm{m}$. 


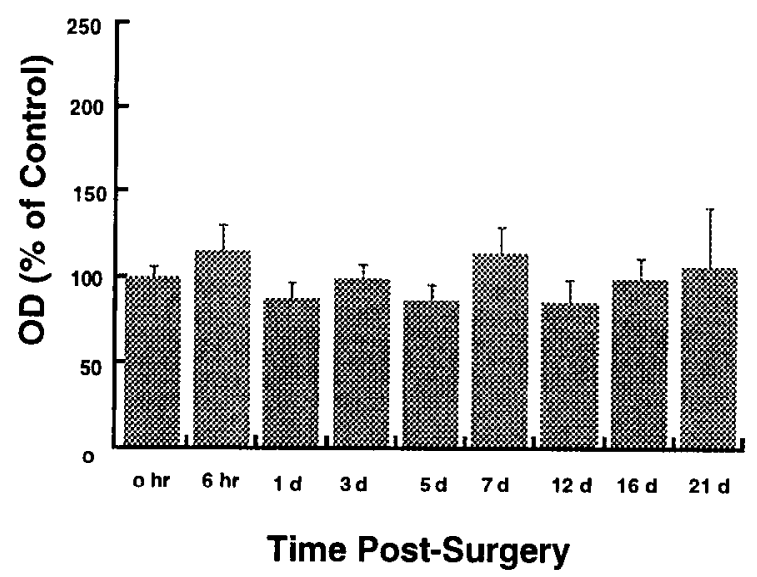

Figure 12. Levels of tenascin immunoreactivity in the dorsolateral striatum after thermocoagulatory lesions of the frontoparietal cortex. Significance was tested with ANOVA and Dunnett's post hoc test. ${ }^{*}, p$ $\leq 0.05$ compared to controls.

in the dentate gyrus of the hippocampus after entorhinal lesions where levels of GAP-43 immunostaining return to control levels between 8 and $30 \mathrm{~d}$ postlesion (Masliah et al., 1991), further supporting evidence that little axonal sprouting occurs in the striatum after cortical aspiration (Chen and Hilman, 1990). The majority of GAP-43 immunostaining in striatum is present in unmyelinated fibers (DiFiglia et al., 1990), suggesting that corticostriatal boutons do not contribute significantly to the overall immunostaining in the striatum. This may explain the absence of significant decreases in GAP-43 at early time points, when only terminal boutons degenerate, both in our and in previous studies (DiFiglia et al., 1990). The delayed decrease in GAP-43 immunoreactivity in the dorsolateral striatum after cortical aspiration is likely related to the degeneration of corticostriatal fibers, which may not be complete until after the first week postsurgery (Olmos et al., 1988). Indeed, although cysts in corticofugal fiber tracts are sometimes observed as early as $5 \mathrm{~d}$ postlesion, they are not usually prominent until day 7 . Because GAP-43 immunoreactivity is also present in some striatal dendrites (DiFiglia et al., 1990), loss of dendritic spines on target neurons that is maximal $10 \mathrm{~d}$ postsurgery (Cheng et al., 1988) may also contribute to the decrease in GAP-43 immunoreactivity (Pasinetti et al., 1993). It is unclear whether the lack of significant decrease in GAP-43 immunoreactivity after thermocoagulatory lesions is due to the presence of growth cones related to axonal sprouting, or to a compensatory increase of GAP-43 levels in spared axonal fibers. In support for this, GAP-43 immu- noreactivity increased in axonal fibers in the corpus callosum, which contains crossed corticostriatal axons, after thermocoagulatory but not aspiration lesions. Electronmicroscopic studies are underway to further test this hypothesis.

The mechanism underlying the differences in the effects of both types of lesions on GAP-43 immunoreactivity in the dorsolateral striatum are unclear. Both types of lesions were of similar size and topography. Lesions by aspiration immediately destroy both neuronal cell bodies and their axons in the cortex. thus resembling lesions of the perforant pathway shown to induce axonal sprouting and reactive synaptogenesis in the dentate gyrus (Matthews et al., 1976; Cotman and Nadler, 1978). In contrast, after thermocoagulatory lesions, corticostriatal inputs degenerate following ischemia-induced (and possibly thermalinduced) death of their ccll bodies, rather than mechanical injury. Although beginning in all cortical layers shortly after surgery, the loss of cortical neurons is progressive and is not complete until 5-7 d postsurgery. Therefore, a major difference between the two types of lesions is that neuronal cell bodies of cortical neurons remain present for some time after thermocoagulatory but not aspiration lesions. Differences in the release of cylokines after both types of lesions could also contribute to the molecular effects observed.

\section{Synaptophysin immunoreactivity}

As previously observed in the mouse (Poltorak et al., 1993) immunolabeling for synaptophysin, a glycoprotein associated with synaptic vesicles (Jahn et al., 1985), did not decrease in dorsolateral striatum after cortical lesions, despite the fact that up to $50 \%$ of synapses are lost in this region (Chen and Hillman, 1990). In contrast to the lack of reactive synaptogenesis, synaptic enlargement occurred in less than $2 \mathrm{~d}$ after cortical aspiration (Chen and Hillman, 1990). Therefore, the absence of changes in the dorsolateral striatum suggests a rapid accumulation of presynaptic vesicles at these enlarged synapses, possibly contributing to the maintenance of synaptic efficacy. Although not documented at the electronmicroscopic level, a similar phenomenon could occur after thermocoagulatory lesions, since synaptophysin immunoreactivity did not change in this situation either. This synaptic plasticity, however, is insufficient to restore homeostasis in the striatum since both types of lesions induced lasting changes in neurotransmitter expression in the striatum (Uhl et al., 1988; Somers and Beackstead, 1990; Salin and Chesselet, 1992, 1993).

bFGF and adhesion molecules

A salient finding of this study is that immunoreactivity to bFGF markedly decreased in the dorsolateral striatum after both types

\footnotetext{
Figure 13. Tenascin and chondroitin sulfate proteoglycan immunoreactivity in white matter after cortical lesions. A, High magnification photomicrograph of tenascin immunoreactivity in a control rat showing positive labeling in the striatal neuropil (small arrows) but lack of tenascin immunoreactivity in a corticofugal fiber tract $(F T) . B-D$. Tenascin immunoreactivity (arrows) in corticofugal fiber tracts $5(B), 12(C)$ and. $21 \mathrm{~d}$ $(D)$, after thermocoagulatory lesions of the frontoparietal cortex. $E$ and $F$, Tenascin immunoreactivity (small arrons) in the corpus callosum (cc) of a control rat $(E)$ and $6 \mathrm{hr}$ after thermocoagulatory lesions of the frontoparietal cortex $(F)$. $G$ and $H$, Chondroitin sulfate proteoglycan immunoreactivity in the corpus callosum of a control rat $(G)$ and $3 \mathrm{~d}(H)$ after thermocoagulatory lesion of the frontoparietal cortex. Scale bars: $15 \mu \mathrm{m}$ $(A-D), 150 \mu \mathrm{m} E$ and $F), 30 \mu \mathrm{m}(G$ and $H)$.

Figure 14. Laminin and PSA-NCAM immunoreactivity in the corpus callosum and striatum after cortical lesions. $A$ and $B$. Laminin immunoreactivity in the vasculature (arrows) of the corpus callosum of a control rat $(A)$ and $3 \mathrm{~d}(B)$ after thermocoagulatory lesion of the frontoparietal cortex. $C$. Laminin immunoreactivity in the dorsolateral striatum of a control rat. $D$, Striatal section processed in the absence of primary antibody. Arrow points to unlabeled blood vessel. $E$, and $F$, Laminin immunoreactivity in denervated striatum $3 \mathrm{~d}$ after thermocoagulatory $(E)$ and $7 \mathrm{~d}$ after aspiration $(F)$ lesions of the frontoparietal cortex. Note the strong laminin immunoreactivity surrounding capillaries (arrows) and the weak immunoreactivity in the neuropil (arrowheads). $G$ and $H$. Absence of detectable PSA-NCAM immunoreactivity in a control rat $(G)$ and $I \mathrm{~d}(H)$ after thermocoagulatory lesion of the frontoparietal cortex. Scale bars: $30 \mu \mathrm{m}(A$ and $B), 60 \mu \mathrm{m}(C-F), 30 \mu \mathrm{m}(E)$, and $15 \mu \mathrm{m}(F)$.
} 

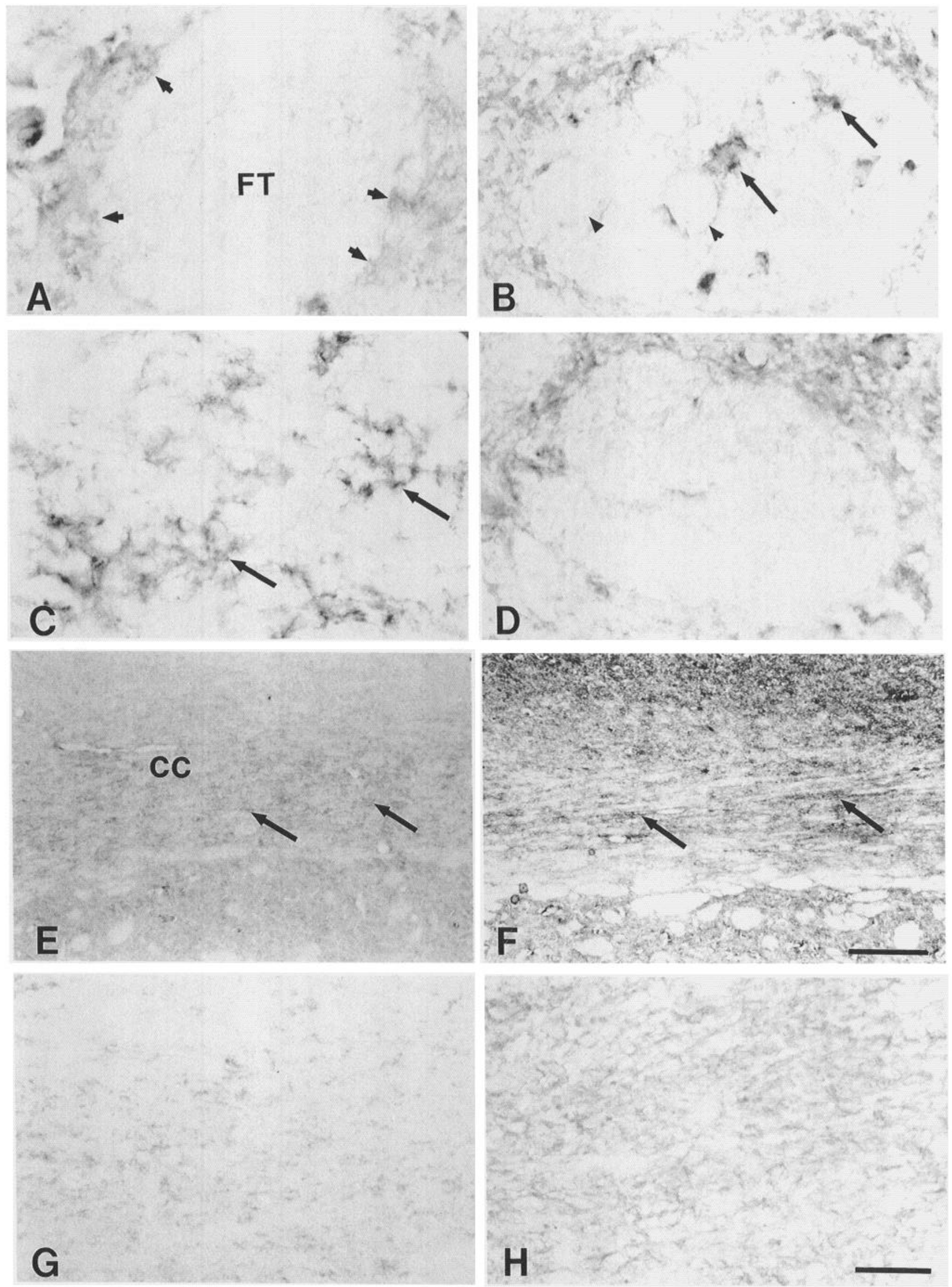


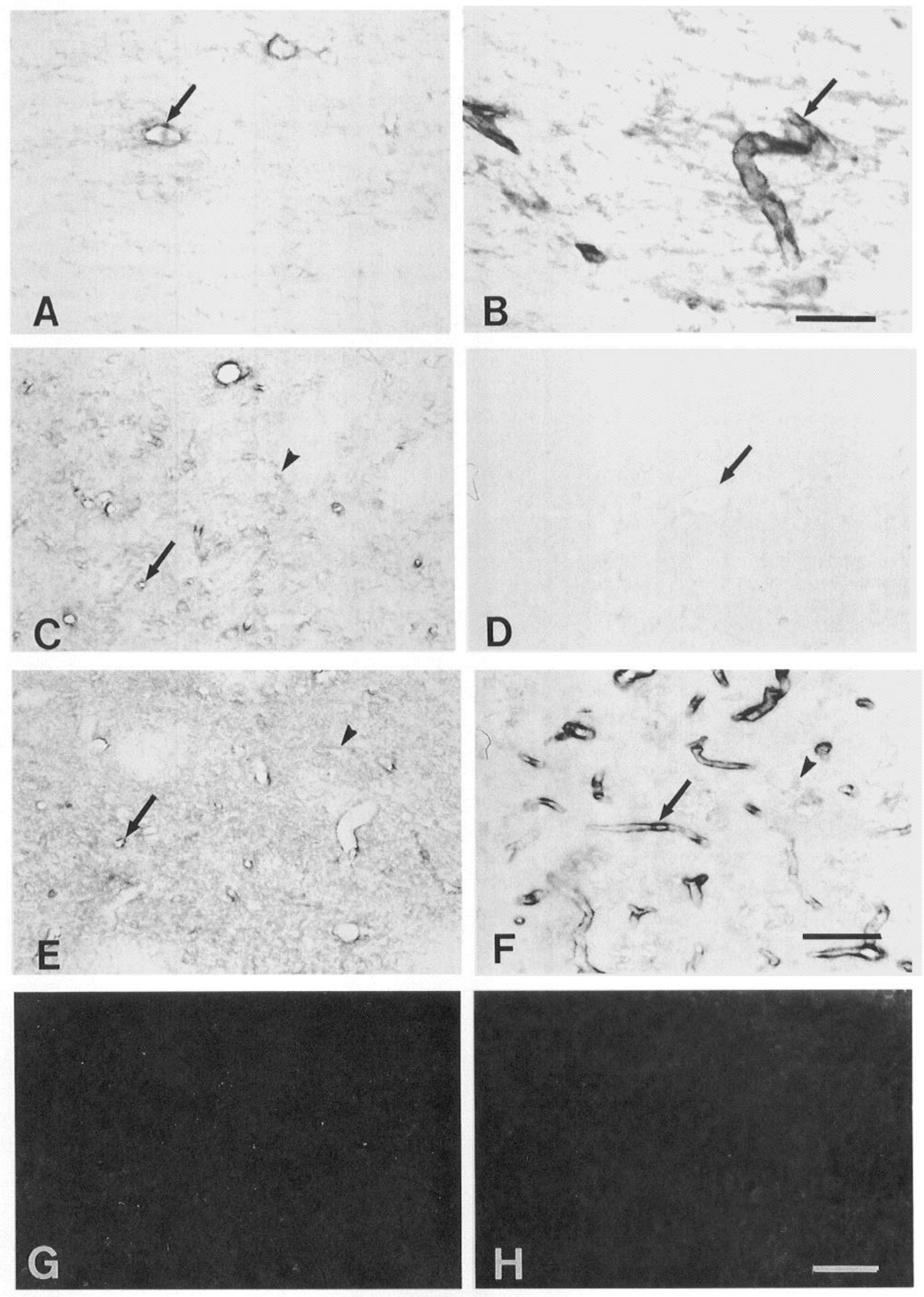


Table 2. Summary of the effects of aspiration versus thermocoagulatory cortical lesions in the neuropil of the dorsolateral striatum

\begin{tabular}{|c|c|c|c|c|c|c|c|c|}
\hline & \multicolumn{2}{|c|}{$\begin{array}{l}\text { Axon terminal } \\
\text { proteins }\end{array}$} & \multicolumn{2}{|c|}{ Glial proteins } & \multicolumn{4}{|c|}{ Adhesion molecules } \\
\hline Aspiration cortical lesion & $\downarrow$ & - & $\uparrow$ & $\downarrow$ & - & - & - & - \\
\hline
\end{tabular}

of lesions, despite the presence of reactive astrocytes. Preliminary studies indicate that the loss of bFGF in striatum is specific to cortical lesion-induced denervation because injections of quinolinic acid in the striatum, which produces a massive loss of striatal ncurons and increased GFAP staining in astrocytes, did not result in similar decreases in bFGF immunoreactivity (Szele and Chesselet, unpublished observations). In the hippocampus, increased expression of bFGF parallels the occurrence of axonal sprouting and the astrocytic response (Gomez-Pinilla et al., 1992). In vitro and in vivo evidence suggest that bFGF can also stimulate neural process outgrowth in the striatum (Takayana et al., 1992; Zhou and DiFiglia, 1993). Therefore, a decreased expression of bFGF after cortical lesions could contribute to limit axonal sprouting in the denervated dorsolateral striatum. It is unlikely that the decrease observed resulted from release of the growth factor since bFGF lacks a signal sequence for secretion. However, it cannot be excluded that the decreased immunostaining resulted from postranslational modifications or changes in subcellular localization of the growth factor. In addition, although the antibody used in this study recognizes the biologically active form of bFGF (Matsuzaki et al., 1989), other isoforms of bFGF, not detected by this antibody, could respond differently to the cortical lesions. Whatever their mechanism, the marked decreases in bFGF immunoreactivity in the dorsolateral striatum after cortical lesions clearly indicate that striatal astrocytes exhibit different molecular responses to loss of afferents than those in other brain regions with robust axonal plasticity.

Another major finding of this study is that the expression of the glial-derived cell adhesion molecule tenascin does not change in the dorsolateral striatum in response to the cortical lesions. This is markedly different from the increased tenascin immunoreactivity observed in reactive astrocytes after direct injury to gray matter in adult brain (Laywell et al., 1992). The effects of tenascin on neurite outgrowth are complex (Lochter et al., 1991). However, the absence of increased tenascin immunoreactivity in the deafferented striatum suggests that striatal astrocytes do not elaborate a substantial barrier for axonal sprouting in this region, as they do in glial scars (McKeon et al., 1991). This is further supported by the absence of increased expression of CSPG, which may also contribute to inhibit neurite outgrowth (Brittis and Silver, 1992). Differences in the pattern of expression of tenascin and CSPG in the dorsolateral striatum versus the white matter tracts are reminiscent of findings by Pindzola ct al. (1993) in the dorsal root entry zone of the spinal cord after root lesions. It is possible that increased expression of CSPG and teneascin in the corpus callosum, and, for tenascin, in the striatum immediately under the corpus callosum, may contribute to inhibit the growth of incoming axons into the striatum. However, the low levels of expression of these molecules in the dorsolateral striatum should not obstruct collateral sprouting of axons within the dorsolateral striatum.

The absence of significant production of glial-derived barrier molecules may not be sufficient to allow for axonal sprouting in the absence of adequate positive influences from growth factors and neurite-promoting adhesion molecules. In contrast to cortical denervation, excitotoxic lesions of the striatum that induce axonal sprouting and rcactivc synaptogenesis (Roberts and DiFiglia, 1990) produce increases in immunohistochemical expression of laminin and PSA-NCAM (Liesi et al., 1984: Uryu and Chesselet, unpublished observations), suggesting that these molecules also favor axonal outgrowth in the striatum as they do in other systems (Doherty et al., 1990; Rivas et al., 1992; Miller et al., 1994; Muller et al., 1994). Thus, in addition to a decreased expression of bFGF, low levels of laminin and absence of PSA-NCAM may contribute to create a molecular environment poorly conducive to axonal sprouting.

\section{Conclusions}

Based on previous evidence, bFGF (Hatten et al., 1988; Takayama et al., 1992) and the panel of adhesion molecules examined (Schwab et al., 1993; Letourneau et al., 1994) are likely to play a role in the initiation and regulation of axonal sprouting in response to partial denervation in vivo. The patterns of expression observed after lesions in the present study suggest that a lack of favorable factors may play a more critical role than the presence of inhibitory molecules to limit axonal sprouting in the denervated striatum after cortical aspiration. The data may lead to novel therapeutic strategies to promote neuronal plasticity in this brain region. This is particularly important in view of the importance of the striatum for motor and cognitive behavior (Evarts and Wise, 1984), and the frequency of cortical lesions secondary to injury, stroke, or atrophy in human pathology.

\section{References}

Aaron LI, Chesselet M-F (1989) Heterogenous distribution of polysialylated neuronal-cell adhesion molecule during post-natal development and in the adult an immunohistochemical study in the rat brain. Neuroscience 28:701-710.

Battisti WP, Bozek K, Rougon G, Murray M (1993) Changes in embryonic NCAM expression following lesions in the adult rat spinal cord. Soc Neurosci Abstr 19:447.

Benowitz LI, Apostolides PJ, Perrone-Bizzozero N, Finklestein SP, Zwiers $\mathrm{H}$ (1988) Anatomical distribution of the growth associated protein GAP-43/B-50 in the adult rat brain. J Neurosci 8:339-352.

Benowitz LI, Rodriguez WR, Neve RL (1990) The pattern of GAP-43 immunostaining changes in the rat hippocampal formation during reactive synaptogenesis. Mol Brain Res 8:17-23.

Bignami A, Eng LF, Dahl D, Uyeda CT (1972) Localization of the glial fibrillary acidic protein in astrocytes by immunofluoresecence. Brain Res 43:429-435.

Bonfanti L, Olive S, Poulain DA, Theodosis DT (1992) Mapping of the distribution of polysialylated neural cell adhesion molecule throughout the central nervous system of the adult rat: an immunohistochemical study. Neuroscience 49:419-436.

Brittis PA, Canning DR, Silver J (1992) Chondroitin sulfate as a regulator of neuronal patterning in retina. Science 255:733-736. 
Chen S, Hillman DE (1990) Robust synaptic plasticity of striatal cells following partial deafferentation. Brain Res 520:103-114.

Cheng HW, Anavi Y, Goshgarian H, McNeill TH, Rafols JA (1988) Loss and recovery of striatal dendritic spines following lesions of the cerebral cortex of adult and aged mice. Soc Neurosci Abstr 14:1219.

Chong MS, Reynolds ML, Irwin N, Coggeshall RE, Emson PC, Benowitz LI. Woolf CJ (1994) GAP-43 Expression in primary sensory neurons following central axotomy. J Neurosci 14:4375-4384.

Chuong C-M, Edelman GM (1984) Alterations in neural cell adhesion molecules during development of different regions of the nervous system. J Neurosci 4:2354-2368.

Cotman C, Nadler JV (1978) Reactive synaptogenesis in the hippocampus. In: Neuronal plasticity (Cotman $\mathrm{CW}$, ed), pp 227-271. New York: Raven.

Curtis R, Green D, Lindsay RM, Wilkin GP (1993) Up-regulation of GAP-43 and growth of axons in rat spinal cord after compression injury. J Neurocytol 22:51-64.

de Olmos JS, Ebbesson SOE, Heimer L (1981) Silver methods for the impregnation of degenerating axoplasm. In: Neuroanatomical tract tracing methods (Heimer L, RoBards MJ, eds), pp 117-170. New York: Plenum.

DiFiglia M. Roberts R, Benowitz LI (1990) Immunoreactive GAP-43 in the neuropil of the adult rat neostriatum: localization in unmyelinated fibers, axon terminals, and dendritic spines. J Comp Neurol 302: 992-1001

Doherty P, Cohen J, Walsh FS (1990) Neurite outgrowth in response to transfected N-CAM changes during development and is modulated by polysialic acid. Neuron 5:209-219.

Dusticier N, Kerkerian L, Errami M, Nieoullon A (1985) Effects of pyroglutamic acid on corticostriatal glutamatergic transmission. Neuropharmacology 24:903-908.

Fckenrode TC, Barr G, Battisti W, Murray M (1987) Acetylcholine in the interpeduncular nucleus of the rat: normal distribution and effects of deafferentation. Brain Res 418:273-286.

Edgar D, Timpl R, Thoenen H (1988) Structural requirements for the stimulation of neurite outgrowth by two variants of laminin and their inhibition by antibodies. J Cell Biol 106:1299-1306.

Errami M, Nieoullon A (1986) Development of a micromethod to study the $\mathrm{Na}^{+}$-independent $\mathrm{L}-\left[{ }^{3} \mathrm{H}\right]$ glutamic acid binding to rat striatal membranes. II. Effects of selective striatal lesions and deafferentations. Brain Res 366:178-186.

Errami M, Nieoullon A (1988) a-[3H]Amino-3-hdroxy-5-methyl-4isoxazolipropionic acid binding to rat striatal membranes: effects of selective brain lesions. J Neurochem 51:579-586.

Faissner A, Kruse J (1990) Jl/Tenascin is a repulsive substrate for central nervous system neurons. Neuron 5:627-637.

Gage FH. Olejniczak P, Armstrong DM (1988) Astrocytes are important for sprouting in the septohippocampal circuit. Exp Neurol 102: $2-13$.

Gomez-Pinilla F, Lee J, Cotman CW (1992) Basic FGF in adult brain: cellular distribution and response to entorhinal lesion and fimbriafornix transection. J Neurosci 12:345-355.

Gomez-Pinilla F, Lee J, Cotman CW (1994) Distribution of the basic fibroblast growth factor in the developing rat brain. Neuroscience 61 : 911-923.

Hatten ME, Lynch M, Rydel RE, Sanchez J, Joseph-Silverstein J, Moscatelli D, Rifkin DB (1988) In vitro neurite extension by granule neurons is dependent on astroglial-derived basic fibroblast growth factor. Dev Biol 125:280-289.

Ilerrera DG, Cuello AC (1992) Glial fibrillary acidic protein immunoreactivity following cortical devascularizing lesions. Neuroscience 49:781-791

Hsu SM, Raine L, Fanger H (1981) Use of avidin-biotin peroxidase complex $(A B C)$ in immunoperoxidase techniques: a comparison between $\mathrm{ABC}$ and unlabelled antibody (PAP) procedures. J Histochem Cytochem 29:577-580.

Jacobson RD, Virag 1, Skene JHP (1986) A protein associated with axon outgrowth, GAP-43, is widely distributed and developmentally regulated in rat CNS. J Neurosci 6:1843-1855.

Jahn R, Sciebler W, Ouimet C, Greengard P (1985) A 38,000-dalton membrane protein $(\mathrm{p} 38)$ present in synaptic vesicles. Proc Natl Acad Sci USA 82:41.37-4141.

Kawaja MD, Gage FH (1991) Reactive astrocytes are substrates for the growth of adult CNS axons in the presence of elevated levels of nerve growth factor. Neuron 7:1019-1030.
Kitagawa K, Matsumoto M, Niinobe M, Mikoshiba K, Hata R. Ueda H, Handa N, Fukunaga K, Isaka Y, Kimura K, Kamada T (1989) Microtubule-associated protein 2 as a sensitive marker for cerebral ischemic damage-immunohistochemical investigation of dendritic damage. Neuroscience 31:401-411.

Kostyk SK, Damore PA, Herman IM, Wagner JA (1994) Optic nerve injury alters basic fibroblast growth factor localization in the retina and optic tract. J Neurosci 14:1441-1449.

Landmesser L, Daum L, Tang J, Rutishauser U (1990) Polysialic acid as a regulator of intramuscular nerve branching during embryonic development. Neuron 4:655-667.

Laywell ED, Dorries U, Bartsch U, Faissner A, Schachner M, Steindler DA (1992) Enhanced expression of the developmentally regulated extracellular matrix molecule tenascin following adult brain injury. Proc Natl Acad Sci USA 98:2634-2638

Le Gal La Salle G, Rougon G, Valin A (1992) The embryonic form of neural cell surface molecule (E-NCAM) in the rat hippocampus and its reexpression on glial cells following kainic acid-induced status epilepticus. J Neurosci 12:872-882.

Letourneau PC, Condic ML, Snow DM (1994) Interactions of developing neurons with extracellular matrix. J Neurosci 14:915-928.

Liesi P (1985) Laminin-immunoreactive glia distinguish regenerative adult CNS systems from non-regenerative ones. EMBO J 4:25052511.

Liesi P, Kaakkola S, Dahl D, Vaheri A (1984) Laminin is induced in astrocytes of adult brain by injury. EMBO J 3:683-686.

Lochter A, Vaughan L, Kaplony A, Prochiantz A, Schachner M, Haissner A (1991) Jl/tenascin in substrate-bound and soluble form displays contrary effects on neurite outgrowth. J Cell Biol 113:11591171 .

Masliah E, Terry RD, Alford M, DeTeresa R (1990) Quantitative immunohistochemistry of synaptophysin in human neocortex: an alternative method to estimate density presynaptic terminals in paraffin sections. J Histochem Cytochem 38:837-844.

Masliah E, Fagan AM, Terry RD, DeTeresa R, Mallory M, Gage FH (1991) Reactive synaptogenesis assessed by synaptophysin immunoreactivity is associated with GAP-43 in the dentate gyrus of the adult rat. Exp Neurol 113:131-142.

Matsuzaki K, Yoshitake Y, Matuo Y, Sasaki H, Nishikawa K (1989) Monoclonal antibodies against heparin-binding growth factor Il/basic fibroblast growth factor that block its biological activity: invalidity of the antibodies for tumor angiogenesis. Proc Natl Acad Sci USA 86:9911-9915.

Matthews DA, Cotman C, Lynch G (1976) An electron microscopic study of lesion-induced synaptogenesis in the dentate gyrus of the adult rat. II. Reappearance of morphologically normal synaptic con tacts. Brain Res 115:23-41.

McGeorge AJ, Faull RLM (1987) The organization and collateralization of corticostriate neurones in the motor and sensory cortex of the rat brain. Brain Res 423:318-324.

McGeorge AJ, Faull RLM (1989) The organization of the projection from the cerebral cortex to the striatum in the rat. Neuroscience 29: 503-537.

McKeon RJ, Schoureiber RC, Rudge JS, Silver J (1991) Reduction of neurite outgrowth in a model of glial scarring following CNS injury is correlated with the expression of inhibitory molecules on reactive astrocytes. J Neurosci 11:3398-3411.

Miller PD, Styren SD, Lagenaur CF, DeKosky ST (1994) Embryonic neural cell adhesion molecule (N-CAM) is elevated in the denervated rat dentate gyrus. J Neurosci 14:4217-4225.

Muller D, Stoppini L, Wang C, Kiss JZ (1994) A role for polysialylated neural cell adhesion molecule in lesion-induced sprouting in hippocampal organotypic cultures. Neuroscience 61:441-445.

Murray M (1993) Plasticity in the spinal cord: the dorsal root connection. Restor Neurol Neurosci 5:7-45.

Pasinetti GM, Cheng HW, Morgan DG, Lampert-Etchells M, McNeill TH, Finch CE (1993) Astrocytic messenger RNA responses to striatal deafferentation in male rat. Neuroscience 53:199-211.

Paxinos G, Watson C (1986) The rat brain in stereotaxic coordinates. Orlando: Academic.

Pindzola RR, Doller C, Silver J (1993) Putative inhibitory extracellular matrix molecules at the dorsal root entry zone of the spinal cord during development and after root and sciatic nerve lesions. Dev Biol 156:34-48.

Poltorak M, Herranz AS, Williams J, Lauretti L, Freed WJ (1993) Ef- 
fects of frontal cortical lesions on mouse striatum: reorganization of cell recognition molecule, glial fiber, and synaptic protein expression in the dorsomedial striatum. J Neurosci 13:2217-2229.

Reier PJ (1986) Gliosis following CNS injury: the anatomy of astrocytic scars and their influences on axonal regeneration. In: Astrocytes, Vol 3 (Federoff S, Vernadakis A, eds), pp 263-324. London: Academic.

Rivas RJ, Burmeister DW, Goldberg DJ (1992) Rapid effects of laminin on the growth cone. Neuron 8:107-115.

Roberts RC, DiFiglia M (1990) Evidence for synaptic proliferation, reorganization, and growth in the excitotoxic lesioned adult rat caudate nucleus. Exp Neurol 107:1-10.

Rougon G, Dubois C, Buckley N, Magnani JL, Zollinger W (1986) A monoclonal antibody raised against meningococcus group $\mathrm{B}$ polysaccharides distinguishes embryonic from adult N-CAM. J Cell Biol 103:2429-2437.

Salin P, Chesselet M-F (1992) Paradoxical increase in striatal neuropeptide gene expression following ischemic lesions of the cerebral cortex. Proc Natl Acad Sci USA 89:9954-9958.

Salin P, Chesselet MF (1993) Expression of GAD (Mr 67,000) and its messenger RNA in basal ganglia and cerebral cortex after ischemic cortical lesions in rats. Exp Neurol 119:291-301.

Salin P, Kerkerian L, Epelbaum J, Nieoullon A (1990) Somatostatinimmunoreactive neurons in the rat striatum: effects of corticostriatal and nigrostriatal dopaminergic lesions. Brain Res 521:23-32.

Schwab ME, Kapfhammer JP, Bandtlow CE (1993) Inhibitors of neurite outgrowth. Annu Rev Neurosci 16:565-595.

Somers DL, Beckstead RM (1990) Striatal preprotachykinin and preproenkephalin mRNA levels and the levels of nigral substance $P$ and pallidal Met ${ }^{5}$-enkephalin depend on corticostriate axons that use the excitatory amino acid neurotransmitters aspartate and glutamate: quantitative radioimmunocytochemical and in situ hybridization evidence. Mol Brain Res 8:143-158.
Steindler DA, Cooper NGF, Faissner A, Schachner M (1989) Boundaries defined by adhesion molecules during development of the cerebral cortex: the $\mathrm{J} 1 /$ tenascin glycoprotein in the mouse somatosensory cortical barrel field. Dev Biol 131:243-260.

Szele FG, Chesselet MF (1994) Cell number and adhesion molecules changes in the subependymal layer after cortical injury. Soc Neurosci Abstr 20:1494.

Szele FG, Dowling JJ, Gonzales C, Theveniau M, Rougon G, Chesselet M-F (1994) Pattern of expression of highly polysialylated neural cell adhesion molecule in the developing and adult rat striatun. Neuroscience $60: 133-144$.

Takayama H, Ray J, Baird A, Beutler AS. Gage FH (1992) Intracerebral grafting of cells genetically modified to express basic fibroblast growth factor. Soc Neurosci Abstr 18:954.

Uhl GR, Navia B, Douglas J (1988) Differential expresion of preproenkephalin and preprodynorphin mRNAs in striatal neurons: high levels of preproenkephalin expresion depend on cerebral cortical afferents. J Neurosci 12:4755-4764.

Vuillet J, Kerkerian L, Kachidian P, Bosler O, Nieoullon A (1989) Ultrastructural correlates of functional relationships between nigral dopaminergic or cortical afferent fibers and neuropeptide $Y$-containing neurons in the rat striatum. Neurosci Lett 100:99-104.

Walaas SI, Jahn R, Greengard P (1988) Quantitation of nerve terminal populations: synaptic vesicle-associated proteins as markers of synaptic density in the rat neostriatum. Synapse 2:516-520.

Woodward WR, Nishi R, Meshul CK, Williams TE, Coulombe M. Eckenstein FP (1992) Nuclear and cytoplasmic localization of basic fibroblast growth factor in astrocytes and CA2 hippocampal neurons J Neurosci 12:142-152.

Zhou D, Difiglia M (1993) Basic fibroblast growth factor enhances the growth of postnatal neostriatal GABAergic neurons in vitro. Exp Neurol 122:171-188. 